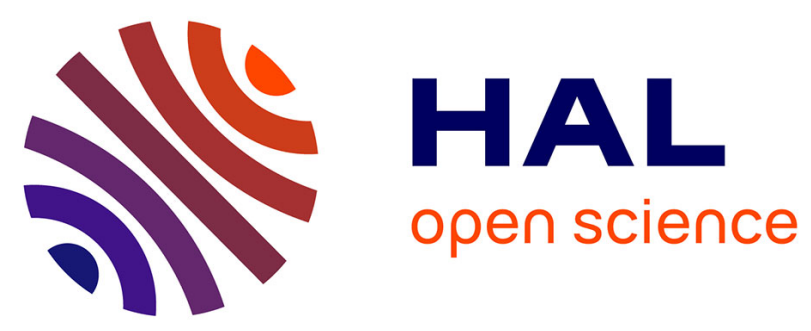

\title{
Development of reduced and optimized reaction mechanism for potassium emissions during pulverized-biomass combustion based on genetic algorithms
}

Kaidi Wan, Luc Vervisch, Chongwen Jiang, Pascale Domingo, Zhenxun Gao, Jun Xia, Zhihua Wang

\section{To cite this version:}

Kaidi Wan, Luc Vervisch, Chongwen Jiang, Pascale Domingo, Zhenxun Gao, et al.. Development of reduced and optimized reaction mechanism for potassium emissions during pulverized-biomass combustion based on genetic algorithms. Energy, 2020, 211, pp.118565. 10.1016/j.energy.2020.118565 . hal-03041419

HAL Id: hal-03041419

https://hal-normandie-univ.archives-ouvertes.fr/hal-03041419

Submitted on 4 Dec 2020

HAL is a multi-disciplinary open access archive for the deposit and dissemination of scientific research documents, whether they are published or not. The documents may come from teaching and research institutions in France or abroad, or from public or private research centers.
L'archive ouverte pluridisciplinaire HAL, est destinée au dépôt et à la diffusion de documents scientifiques de niveau recherche, publiés ou non, émanant des établissements d'enseignement et de recherche français ou étrangers, des laboratoires publics ou privés. 


\title{
Development of reduced and optimized reaction mechanism for potassium emissions during pulverized-biomass combustion based on genetic algorithms
}

\author{
Kaidi Wan ${ }^{\mathrm{a}, \mathrm{b}, *}$, Luc Vervisch ${ }^{\mathrm{c}}$, Chongwen Jiang ${ }^{\mathrm{a}, \mathrm{b}}$, Pascale Domingo ${ }^{\mathrm{c}}$, Zhenxun Gao ${ }^{\mathrm{a}, \mathrm{b}}$, Jun Xia ${ }^{\mathrm{e}}$, \\ Zhihua Wang ${ }^{\mathrm{d}}$ \\ ${ }^{a}$ Aircraft and Propulsion Laboratory, Ningbo Institute of Technology, Beihang University, Ningbo 315832, China \\ ${ }^{b}$ National Laboratory for Computational Fluid Dynamics, School of Aeronautic Science and Engineering, Beihang \\ University, Beijing 100191, China \\ ${ }^{c}$ CORIA - CNRS, Normandie Université, INSA de Rouen, 76801 Saint-Etienne-du-Rouvray, France \\ ${ }^{d}$ State Key Laboratory of Clean Energy Utilization, Zhejiang University, Hangzhou 310027, China \\ ${ }^{e}$ Department of Mechanical and Aerospace Engineering $\mathcal{G}$ Institute of Energy Futures, Brunel University London, \\ Uxbridge UB8 $3 \mathrm{PH}, \mathrm{UK}$
}

\begin{abstract}
A reduced mechanism for potassium chemistry under combustion conditions is derived from a detailed chemical mechanism for alkali metal emissions (Glarborg and Marshall, 2005), which could be useful for three-dimensional (3D) numerical simulations of potassium emissions by biomass combustion furnaces. An automated chemistry reduction and optimization approach relying on canonical micro-mixing problem is applied to develop the reduced mechanism, whose performance is then evaluated in two-dimensional (2D) carrier-phase direct numerical simulation (DNS) of pulverized-biomass combustion. Good agreements are achieved between predictions of the reduced and the detailed mechanisms on the four major potassium species, i.e., $\mathrm{K}, \mathrm{KOH}, \mathrm{KCl}$ and $\mathrm{K}_{2} \mathrm{SO}_{4}$. The prediction capabilities of the reduced mechanism for various $\mathrm{K} / \mathrm{Cl} / \mathrm{S}$ ratios in the volatiles are further investigated by a parametric study with 14 two-dimensional DNS cases. The potassium chemistry under those various conditions are predicted well by the reduced potassium mechanism with a CPU cost reduction reaching up to $71.3 \%$ compared to the detailed reference mechanism.

Keywords: Pulverized-biomass combustion, Direct numerical simulation, Potassium, Chemistry reduction, Genetic algorithm
\end{abstract}




\section{Introduction}

As a carbon neutral fuel, biomass resource is attracting more attention recently due to the urgent requirement of reducing $\mathrm{CO}_{2}$ emissions to control global warming [1-3]. Nowadays, biomass and its thermal-conversion products, e.g. solid/liquid biofuels and biogases, already contribute $10 \%$ of the world total primary energy supply [4]. Biomass could substitute coal in most present coal-fired power plants without reconstruction, with a maximum mass ratio of biomass about 20$30 \%$ [5]. On the other hand, because of the relatively high alkali metal content in biomass, alkaliinduced slagging issue becomes one of the most challenging problems in the practical thermoutilization of biomass [6, 7], especially for herbaceous plants which are rich in potassium (K) [8]. During the combustion of biomass, alkali species can be released into gas phase and then condense on heat exchange surfaces of the furnace, which generates an initial sticky layer and then captures fly ash resulting in rapid ash deposition [9, 10]. Besides, fouling and corrosion issues are also found due to high chemical activity of chlorine and sulfur compounds of alkali, e.g., $\mathrm{KCl}$ [11]. These alkali-induced issues severely limit the clean and efficient utilization of biomass resources.

Over the past decades, experimental measurements on alkali chemistry during biomass combustion evolves from offline sampling to online laser diagnostics techniques [12-14]. The timeresolved alkali release process during the combustion can be directly captured by using the online laser techniques, e.g., tunable diode laser absorption spectroscopy (TDLAS) [15], and collinear photofragmentation and atomic absorption spectroscopy (CPFAAS) [16]. Recently, Liu et al. [17] applied planar laser-induced fluorescence (PLIF) and multi-point laser-induced breakdown spectroscopy (LIBS) methods to quantitatively measure the atomic and elemental potassium released from a burning biomass pellet. Weng et al. [18] measured the spatial distribution of potassium hydroxide $(\mathrm{KOH})$ and potassium chloride $(\mathrm{KCl})$ simultaneously around single burning pulverized biomass char particles by employing laser-induced photofragmentation fluorescence (LIPF) technique.

On the modeling side, one-step and two-step Arrhenius potassium release models have been developed for biomass pellet combustion by Zhang et al. [19] and Liu et al. [17], respectively.

\footnotetext{
${ }^{*}$ Corresponding author

Email address: wankaidi@buaa.edu.cn (Kaidi Wan)
} 
These models are suitable to describe potassium release of biomass in typical circulating fluidized bed (CFB) combustion, as the diameter and burnout time of biomass in these studies are with the same order of magnitude of biomass fuel in a typical CFB boiler [20].

To describe the post-release alkali reaction dynamics during combustion, the first detailed alkali mechanisms were developed by Srinivasachar et al. [21] and Steinberg and Schofield [22]. Based on that, Glarborg and Marshall [23] proposed a detailed alkali mechanism encompassing the elements $\mathrm{Na}, \mathrm{K}, \mathrm{C}, \mathrm{H}, \mathrm{O}, \mathrm{S}$ and $\mathrm{Cl}$, and it was carefully validated against the experimental results of homogeneous sulfation of alkali chloride under combustion conditions [24]. However, the complexity of this reference detailed alkali mechanism [23], which includes $48 \mathrm{Na} / \mathrm{K} / \mathrm{O} / \mathrm{H} / \mathrm{Cl} / \mathrm{S}$ species and 202 elementary reactions, largely limits its application in computational fluid dynamic (CFD) simulations. Hence, in the literature the reported CFD simulations of real combustion systems with alkali reactions employed simplified versions of the detailed mechanism. Akbar et al. [25] employed a $\mathrm{K} / \mathrm{O} / \mathrm{H} / \mathrm{Cl}$ subset with 14 reactions to predict the potassium reactions in a 0.5 MW pulverized-fuel combustion facility using Reynolds-Averaged Navier-Stokes (RANS) simulations. Garba et al. [26] developed a reduced mechanism containing $36 \mathrm{~K} / \mathrm{O} / \mathrm{H} / \mathrm{Cl} / \mathrm{S}$ species and 137 reactions using sensitivity analysis and applied it to RANS simulations of a $10 \mathrm{MW}$ biomass-fired furnace. However, to the best of our knowledge, a systematic reduction study of the detailed alkali mechanism for biomass combustion has not been reported yet, which could potentially benefit the CFD investigations of biomass furnaces.

Within this context and considering only one alkali metal, $\mathrm{K}$, for biomass combustion, the aim of the present study is twofold. First, a reduced potassium mechanism is developed from the detailed one by Glarborg and Marshall [23] using systematic chemistry reduction and rate optimization techniques [27, 28]. Second, the performance of the reduced mechanism is then carefully examined in two-dimensional (2D) direct numerical simulations (DNS) of pulverizedbiomass combustion.

\section{Automated reduction and optimization of potassium reaction kinetics}

The potassium reaction dynamics during the combustion of biomass volatile is investigated. The volatile of corn straw [17] is employed, for which the chemical properties are shown in Table 
Table 1: Properties of corn straw [10]

\begin{tabular}{|c|c|c|c|c|c|c|c|c|c|}
\hline \multicolumn{5}{|c|}{ Proximate analysis (wt\%) } & \multicolumn{5}{|c|}{ Ultimate analysis (wt\%) } \\
\hline $\mathrm{M}_{\mathrm{ad}}$ & $\mathrm{A}_{\mathrm{ad}}$ & $\mathrm{V}_{\mathrm{ad}}$ & $\mathrm{FC}_{\mathrm{ad}}$ & & $\mathrm{C}_{\mathrm{daf}}$ & $\mathrm{H}_{\text {daf }}$ & $\mathrm{N}_{\mathrm{daf}}$ & $S_{\text {daf }}$ & $\mathrm{O}_{\mathrm{daf}}$ \\
\hline 11.6 & 7.9 & 64.2 & 16.3 & & 43.9 & 4.5 & 1.8 & 0.4 & 49.3 \\
\hline $\begin{array}{l}\text { Ash ar } \\
\mathrm{SiO}_{2}\end{array}$ & $\begin{array}{l}\text { alysis }( \\
\mathrm{Al}_{2} \mathrm{O}_{3}\end{array}$ & $\begin{array}{l}\mathrm{t} \%) \\
\mathrm{Fe}_{2} \mathrm{O}_{3}\end{array}$ & $\mathrm{CaO}$ & $\mathrm{MgO}$ & $\mathrm{K}_{2} \mathrm{O}$ & $\mathrm{Na}_{2} \mathrm{O}$ & & $\begin{array}{l}\mathrm{Cl}_{\mathrm{ad}} \\
(\mathrm{mg} / \mathrm{g})\end{array}$ & $\begin{array}{l}\mathrm{K}_{\mathrm{ad}} \\
(\mathrm{mg} / \mathrm{g})\end{array}$ \\
\hline 47.52 & 5.64 & 1.04 & 4.51 & 12.6 & 7.87 & 1.97 & & 1.34 & 13.1 \\
\hline
\end{tabular}

Table 2: Modeled volatile compositions of corn straw.

\begin{tabular}{llllll}
\hline \multicolumn{5}{l}{ Hydrocarbon volatile compositions (mass fractions) } \\
$\mathrm{CH}_{4}$ & $\mathrm{C}_{2} \mathrm{H}_{2}$ & $\mathrm{CO}$ & $\mathrm{H}_{2}$ & $\mathrm{CO}_{2}$ & $\mathrm{H}_{2} \mathrm{O}$ \\
\hline 0.0322 & 0.1805 & 0.2536 & 0.0215 & 0.1853 & 0.3024 \\
\hline \multicolumn{5}{l}{ Non-hydrocarbon volatile compositions (mass fractions) } \\
$\mathrm{KOH}$ & $\mathrm{HCl}$ & $\mathrm{SO}_{2}$ & & & \\
\hline 0.0147 & 0.0018 & 0.0080 & \\
\hline
\end{tabular}

1. The previously validated DRM22 mechanism proposed by Kazakov and Frenklach [29] is used to describe the hydrocarbon combustion of the volatile, which contains 22 chemical species and 104 elementary reactions. The compositions of the hydrocarbon volatile are preliminary determined via the bio-chemical percolation devolatilization (bio-CPD) model [30-32], with the Tar species replaced by $\mathrm{C}_{2} \mathrm{H}_{2}$ [33]. Then minor adjustments are applied to the compositions to fulfill the elemental mass conservation and the lower heating value of the corn straw [34]. The final volatile compositions are given in Table 2 .

Following previous researches on sodium emissions by coal combustion [35], the initial potassium species in the volatile is set to be $\mathrm{KOH}$, while those of $\mathrm{S}$ and $\mathrm{Cl}$ are set to be $\mathrm{SO}_{2}$ and $\mathrm{HCl}$, respectively. According to the experimental results [17], 58.1\% of the mass of potassium present in the biomass is released during pyrolysis. However, no experimental information is available for the release of chlorine and sulfur. Here, they are assumed to follow the ratio of volatile yields during pyrolysis as predicted by the bio-CPD model, i.e., $87.3 \%$ of the mass of chlorine and sulfur is released along with the volatiles. The mass fractions of $\mathrm{KOH}, \mathrm{HCl}$ and $\mathrm{SO}_{2}$ in the volatile can then be computed, as summarized in Table 2 .

The reactions of $\mathrm{K} / \mathrm{S} / \mathrm{Cl}$ species are simulated using the detailed mechanism by Glarborg and 
Marshall [23] containing the elements $\mathrm{Na}, \mathrm{K}, \mathrm{C}, \mathrm{H}, \mathrm{O}, \mathrm{S}$ and $\mathrm{Cl}$. In this work, the element $\mathrm{Na}$ is not considered, which leads to a reference detailed mechanism of potassium reactions involving 35 species and 153 elementary reactions.

\subsection{Stochastic micro-mixing problem}

To develop a reduced potassium mechanism which can be applied under a wide range of conditions, a turbulent non-premixed micro-mixing based canonical problem is introduced as a reference problem for the reduction of the reference detailed mechanism. This approach has been detailed in Jaouen et al. [27], and only the core idea is given here.

Within a Lagrangian framework, the time evolution of the composition and energy of a traveling fluid particle can be computed with the diffusive budget described by a deterministic micromixing closure, as the linear relaxation model (IEM or LMSE) [36, 37]:

$$
\frac{d \varphi^{L}(t)}{d t}=\frac{\langle\varphi\rangle(t)-\varphi^{L}(t)}{\tau_{T}}+\dot{\omega}_{\varphi}
$$

where $\varphi$ is a thermochemical variable, i.e., species mass fractions and temperature, while $\langle\varphi\rangle$ is the mean flow condition seen by the traveling particles at a given time. $\dot{\omega}_{\varphi}$ is the chemical source of $\varphi$ and $\tau_{T}$ is a characteristic turbulent mixing time. Solving for Eq. (1) starting from initial conditions, e.g., pure fuel, oxidizer or burnt gases, a trajectory $\varphi^{L}(t)$ can be obtained. The average mixture environment seen during the trajectory is characterized by [27]

$$
\langle\varphi\rangle(t)=\frac{1}{N_{p}} \sum_{p=1}^{N_{p}} \varphi^{p}(t)
$$

where $\varphi^{p}(t)\left(p=1, \cdots, N_{p}\right)$ is a set of stochastic particles whose thermochemical properties evolve according to chemical reactions and a micro-mixing closure, here the well-known Curl closure [38] is employed. The time evolutions of those stochastic particles are solved aside from any simulation in physical space, to cover the range of the representative composition space of the flow problem under investigation. Initially, the $N_{p}$ stochastic particles are divided into $n_{I}$ groups, with $n_{I}$ the number of inlets. The number of particles for each inlet is determined according to the relative 
contribution of the inlet to the total mass flow rate of the flow problem. The particles assigned to a given inlet take the species composition and temperature of that inlet. In addition, some particles may be set with burnt gases conditions to secure ignition and/or mimic dilution by burnt gases. Then a deterministic trajectory $\varphi^{L}(t)$ can be computed from every inlet (Eq. 1). This micromixing based canonical approach of analyzing the response of reduced chemical mechanisms has been previously applied to a four inlets methane/vitiated-air/hydrogen-air/steam combustion system [27].

The operating conditions of the micro-mixing problem in the present study are those of the pulverized-biomass jet flame studied in [39], which are also adopted thereafter for DNS. Three inlet streams are involved, i.e., the oxidizer air, the fuel volatile and a high-temperature third inlet. The volatile composition (see Table 2) of corn straw is employed and the third inlet is the burnout gas of the volatile and air at $\phi=0.45$. The mass flow rate of the three inlets, i.e., the number of particles per inlet, is chosen so that the overall system operates under the stoichiometric condition. In total 500 particles is employed, and $4 \%$ of them are initially set to the chemical equilibrium condition at $\phi=1$, to secure ignition. The micro-mixing time $\tau_{t}$ is set to $0.2 \mathrm{~ms}$, with a weak sensitivity of the obtained reduced mechanism to this parameter, as soon as its value allows for ignition (see [27] for a sensitivity analysis on $\tau_{t}$ ).

The ORCh (Optimized and Reduced Chemistry) method, reported in detail in [27, 28] and previously employed for modeling meso-scale combustion [40] and selective non-catalytic reduction [41], is coupled with the CANTERA [42] chemical kinetics solver. ORCh consists of a combination of Directed Relation Graph with Error Propagation (DRGEP) [43, 44] analyses, to which a Genetic Algorithm (GA) [45] is added to optimize the chemical rates parameters of the reduced mechanism.

\subsection{DRGEP}

First, the species and elementary reactions which make a minor contribution to the stochastic micro-mixing problem are removed by the DRGEP approach. The details of DRGEP can be found in the seminal papers by Lu and Law [43] and Pepiot and Pitsch [44]. Here, only the main lines are given as follows. 
First, a set of target species is defined, from the species which need to be predicted accurately by the reduced mechanism. Here, it includes the four major potassium species $\mathrm{K}, \mathrm{KOH}, \mathrm{KCl}$ and $\mathrm{K}_{2} \mathrm{SO}_{4}$. Then, species and reactions are automatically ordered according to their relative influence on the evolution of the target species listed above, which is obtained by comparing the variation rate of a target species when a non-target species or elementary reaction is involved against the total variation rate of that target species [44].

Starting from the least important one, the species and reactions are progressively removed from the detailed mechanism and the deterministic trajectory $\varphi_{k}^{L}\left(t_{\ell} ; n\right)($ Eq. 1 ) is re-computed after each removing operation. $k$ denotes the $k$-th targeted thermochemical property $\left(k=1, \cdots, N_{t}=4\right), t_{\ell}$ is the $\ell$-th point $\left(\ell=1, \cdots, N_{\ell}=1000\right)$ of a chemical trajectory versus time, $n$ denotes the $n$-th inlet $\left(n=1, \cdots, N_{I}=3\right)$. The obtained distributions of $\varphi_{k}^{L}\left(t_{\ell} ; n\right)$ of the target species mass fractions are compared against $\varphi_{k}^{\operatorname{Ref}}\left(t_{\ell} ; n\right)$, and the error measure is calculated as:

$$
E=\frac{1}{N_{I} \cdot N_{t} \cdot N_{\ell}} \sum_{n=1}^{N_{I}} \sum_{k=1}^{N_{t}} \sum_{\ell=1}^{N_{\ell}}\left|\frac{\varphi_{k}^{\operatorname{Ref}}\left(t_{\ell} ; n\right)-\varphi_{k}^{L}\left(t_{\ell} ; n\right)}{\varphi_{k}^{\operatorname{Ref}}\left(t_{\ell} ; n\right)}\right|
$$

With the error threshold $E=0.1 \%, 20 \mathrm{~K} / \mathrm{S} / \mathrm{Cl}$ species are removed during the DRGEP reduction, resulting in $15 \mathrm{~K} / \mathrm{S} / \mathrm{Cl}$ species. Then, the number of reactions is further downsized to 24 with $E=0.96 \%$ (Table 3, but using the original rates parameters from [23]).

During DRGEP, 7 elementary reactions are chosen as the most important ones over the original 23 reactions of the detailed mechanism for the $\mathrm{K} / \mathrm{C} / \mathrm{H} / \mathrm{O}$ subsystem:

$$
\begin{aligned}
& \mathrm{K}+\mathrm{O}_{2}(+\mathrm{M}) \rightleftharpoons \mathrm{KO}_{2}(+\mathrm{M}) \\
& \mathrm{H}_{2} \mathrm{O}+\mathrm{KO} \rightleftharpoons \mathrm{KOH}+\mathrm{OH} \\
& \mathrm{CO}+\mathrm{KO} \rightleftharpoons \mathrm{CO}_{2}+\mathrm{K} \\
& \mathrm{H}+\mathrm{KOH} \rightleftharpoons \mathrm{H}_{2} \mathrm{O}+\mathrm{K} \\
& 2 \mathrm{KOH} \rightleftharpoons \mathrm{K}_{2} \mathrm{O}_{2} \mathrm{H}_{2} \\
& \mathrm{H}+\mathrm{KO}_{2} \rightleftharpoons \mathrm{HO}_{2}+\mathrm{K} \\
& \mathrm{CO}+\mathrm{KO}_{2} \rightleftharpoons \mathrm{CO}_{2}+\mathrm{KO}
\end{aligned}
$$

In this subsystem, the reactions between $\mathrm{KOH}$ and the radicals $\mathrm{OH}$ and $\mathrm{H}(\mathrm{R} 2, \mathrm{R} 4)$ are kept along with the equilibrium between $\mathrm{KOH}$ and $\mathrm{K}_{2} \mathrm{O}_{2} \mathrm{H}_{2}$ (R5). $\mathrm{KO}_{2}$ is formed via the three-body reaction 
(R1) and reacts with radical $\mathrm{H}$ and $\mathrm{CO}(\mathrm{R} 6, \mathrm{R} 7)$. The reduction reaction of $\mathrm{KO}$ by $\mathrm{CO}$ is also kept (R3). In the $\mathrm{K} / \mathrm{H} / \mathrm{O} / \mathrm{Cl}$ subsystem, 4 elementary reactions over the 10 original ones enter the reduced mechanism, which produce $\mathrm{KCl}$ from $\mathrm{HCl}$ and $\mathrm{K}(\mathrm{R} 8), \mathrm{KOH}(\mathrm{R} 9)$ and $\mathrm{KO}_{2}(\mathrm{R} 10)$ and secure the equilibrium between $\mathrm{KCl}$ and $\mathrm{K}_{2} \mathrm{Cl}_{2}(\mathrm{R} 11)$ :

$\mathrm{HCl}+\mathrm{K} \rightleftharpoons \mathrm{H}+\mathrm{KCl}$

$\mathrm{HCl}+\mathrm{KOH} \rightleftharpoons \mathrm{H}_{2} \mathrm{O}+\mathrm{KCl}$

$\mathrm{HCl}+\mathrm{KO}_{2} \rightleftharpoons \mathrm{HO}_{2}+\mathrm{KCl}$

$2 \mathrm{KCl} \rightleftharpoons \mathrm{K}_{2} \mathrm{Cl}_{2}$

Over the 17 reactions of $\mathrm{K} / \mathrm{H} / \mathrm{O} / \mathrm{Cl} / \mathrm{S}$ subsystem, 7 are required by the reduced mechanism: 2 three-body reactions producing $\mathrm{KSO}_{3}(\mathrm{R} 12, \mathrm{R} 13)$ and one producing $\mathrm{KHSO}_{4}$ (R14); 3 reactions contribute to the formation of $\mathrm{K}_{2} \mathrm{SO}_{4}$ (R16, R17, R18); the reaction between $\mathrm{KSO}_{3}$ and radical $\mathrm{OH}(\mathrm{R} 15)$.

$$
\begin{aligned}
& \mathrm{K}+\mathrm{SO}_{3}(+\mathrm{M}) \rightleftharpoons \mathrm{KSO}_{3}(+\mathrm{M}) \\
& \mathrm{KO}+\mathrm{SO}_{2}(+\mathrm{M}) \rightleftharpoons \mathrm{KSO}_{3}(+\mathrm{M}) \\
& \mathrm{KOH}+\mathrm{SO}_{3}(+\mathrm{M}) \rightleftharpoons \mathrm{KHSO}_{4}(+\mathrm{M}) \\
& \mathrm{KSO}_{3}+\mathrm{OH} \rightleftharpoons \mathrm{KOH}+\mathrm{SO}_{3} \\
& \mathrm{KO}+\mathrm{KSO}_{3} \rightleftharpoons \mathrm{K}_{2} \mathrm{SO}_{4} \\
& \mathrm{KHSO}{ }_{4}+\mathrm{KOH} \rightleftharpoons \mathrm{H}_{2} \mathrm{O}+\mathrm{K}_{2} \mathrm{SO}_{4} \\
& \mathrm{KCl}+\mathrm{KHSO}_{4} \rightleftharpoons \mathrm{HCl}+\mathrm{K}_{2} \mathrm{SO}_{4}
\end{aligned}
$$

4 elementary reactions driving the oxidation of sulfur containing species (R19 to R22) are included in the $\mathrm{SO}_{2} / \mathrm{SO}_{3}$ interconversion subsystem of the reduced mechanism:

$$
\begin{aligned}
& \mathrm{HOSO}_{2}+\mathrm{O}_{2} \rightleftharpoons \mathrm{HO}_{2}+\mathrm{SO}_{3} \\
& \mathrm{O}+\mathrm{SO}_{2}(+\mathrm{M}) \rightleftharpoons \mathrm{SO}_{3}(+\mathrm{M}) \\
& \mathrm{OH}+\mathrm{SO}_{2}(+\mathrm{M}) \rightleftharpoons \mathrm{HOSO}_{2}(+\mathrm{M}) \\
& \mathrm{OH}+\mathrm{SO}_{2} \rightleftharpoons \mathrm{H}+\mathrm{SO}_{3}
\end{aligned}
$$

Finally, the $\mathrm{H} / \mathrm{O} / \mathrm{Cl}$ subsystem requires only one three-body (R23) and one replacement reactions (R24) in the reduced mechanism:

$$
\begin{aligned}
& \mathrm{HCl}+\mathrm{M} \rightleftharpoons \mathrm{Cl}+\mathrm{H}+\mathrm{M} \\
& \mathrm{HCl}+\mathrm{OH} \rightleftharpoons \mathrm{Cl}+\mathrm{H}_{2} \mathrm{O}
\end{aligned}
$$


Table 3: The $15 \mathrm{~K} / \mathrm{S} / \mathrm{Cl}$ species and 24 reactions mechanism reduced by DRGEP and kinetic rates optimized by genetic algorithm over a stochastic micro-mixing problem. Units are mol, $\mathrm{s}, \mathrm{cm}^{3}$, cal and $\mathrm{K}$. The Chaperon efficiencies of the reference mechanism [23] are preserved for both three-body and fall-off reactions. Electronic format available in the supplementary material.

\begin{tabular}{|c|c|c|c|c|}
\hline & Reaction & $A$ & $\beta$ & $E$ \\
\hline 1 & $\mathrm{~K}+\mathrm{O}_{2}(+\mathrm{M}) \rightleftharpoons \mathrm{KO}_{2}(+\mathrm{M})$ & $5.84 \mathrm{e}+13$ & 0 & 0 \\
\hline 2 & $\mathrm{H}_{2} \mathrm{O}+\mathrm{KO} \rightleftharpoons \mathrm{KOH}+\mathrm{OH}$ & $1.85 \mathrm{e}+14$ & 0 & 0 \\
\hline 3 & $\mathrm{CO}+\mathrm{KO} \rightleftharpoons \mathrm{CO}_{2}+\mathrm{K}$ & $2.81 \mathrm{e}+13$ & 0 & 0 \\
\hline 4 & $\mathrm{H}+\mathrm{KOH} \rightleftharpoons \mathrm{H}_{2} \mathrm{O}+\mathrm{K}$ & $5.17 e+13$ & 0 & 0 \\
\hline 5 & $2 \mathrm{KOH} \rightleftharpoons \mathrm{K}_{2} \mathrm{O}_{2} \mathrm{H}_{2}$ & $8.00 \mathrm{e}+13$ & 0 & 0 \\
\hline 6 & $\mathrm{H}+\mathrm{KO}_{2} \rightleftharpoons \mathrm{HO}_{2}+\mathrm{K}$ & $3.92 \mathrm{e}+14$ & 0 & 0 \\
\hline 7 & $\mathrm{CO}+\mathrm{KO}_{2} \rightleftharpoons \mathrm{CO}_{2}+\mathrm{KO}$ & $1.96 \mathrm{e}+14$ & 0 & 0 \\
\hline 8 & $\mathrm{HCl}+\mathrm{K} \rightleftharpoons \mathrm{H}+\mathrm{KCl}$ & $1.02 \mathrm{e}+14$ & 0 & 3717 \\
\hline 9 & $\mathrm{HCl}+\mathrm{KOH} \rightleftharpoons \mathrm{H}_{2} \mathrm{O}+\mathrm{KCl}$ & $1.72 \mathrm{e}+14$ & 0 & 0 \\
\hline 10 & $\mathrm{HCl}+\mathrm{KO}_{2} \rightleftharpoons \mathrm{HO}_{2}+\mathrm{KCl}$ & $1.12 \mathrm{e}+14$ & 0 & 0 \\
\hline 11 & $2 \mathrm{KCl} \rightleftharpoons \mathrm{K}_{2} \mathrm{Cl}_{2}$ & $8.00 \mathrm{e}+13$ & 0 & 0 \\
\hline 12 & $\mathrm{~K}+\mathrm{SO}_{3}(+\mathrm{M}) \rightleftharpoons \mathrm{KSO}_{3}(+\mathrm{M})$ & $8.32 \mathrm{e}+13$ & 0 & 0 \\
\hline 13 & $\mathrm{KO}+\mathrm{SO}_{2}(+\mathrm{M}) \rightleftharpoons \mathrm{KSO}_{3}(+\mathrm{M})$ & $7.91 \mathrm{e}+14$ & 0 & 0 \\
\hline 14 & $\mathrm{KOH}+\mathrm{SO}_{3}(+\mathrm{M}) \rightleftharpoons \mathrm{KHSO}_{4}(+\mathrm{M})$ & $1.13 \mathrm{e}+14$ & 0 & 0 \\
\hline 15 & $\mathrm{KSO}_{3}+\mathrm{OH} \rightleftharpoons \mathrm{KOH}+\mathrm{SO}_{3}$ & $1.18 \mathrm{e}+13$ & 0 & 0 \\
\hline 16 & $\mathrm{KO}+\mathrm{KSO}_{3} \rightleftharpoons \mathrm{K}_{2} \mathrm{SO}_{4}$ & $7.25 \mathrm{e}+14$ & 0 & 0 \\
\hline 17 & $\mathrm{KHSO}_{4}+\mathrm{KOH} \rightleftharpoons \mathrm{H}_{2} \mathrm{O}+\mathrm{K}_{2} \mathrm{SO}_{4}$ & $1.19 \mathrm{e}+14$ & 0 & 0 \\
\hline 18 & $\mathrm{KCl}+\mathrm{KHSO}_{4} \rightleftharpoons \mathrm{HCl}+\mathrm{K}_{2} \mathrm{SO}_{4}$ & $4.83 e+13$ & 0 & 0 \\
\hline 19 & $\mathrm{HOSO}_{2}+\mathrm{O}_{2} \rightleftharpoons \mathrm{HO}_{2}+\mathrm{SO}_{3}$ & $1.32 \mathrm{e}+12$ & 0 & 615 \\
\hline 20 & $\mathrm{O}+\mathrm{SO}_{2}(+\mathrm{M}) \rightleftharpoons \mathrm{SO}_{3}(+\mathrm{M})$ & $1.34 \mathrm{e}+10$ & 0 & 1563 \\
\hline 21 & $\mathrm{OH}+\mathrm{SO}_{2}(+\mathrm{M}) \rightleftharpoons \mathrm{HOSO}_{2}(+\mathrm{M})$ & $7.63 e+12$ & 0 & 691 \\
\hline 22 & $\mathrm{OH}+\mathrm{SO}_{2} \rightleftharpoons \mathrm{H}+\mathrm{SO}_{3}$ & $4.90 \mathrm{e}+02$ & 2.54 & 23681 \\
\hline 23 & $\mathrm{HCl}+\mathrm{M} \rightleftharpoons \mathrm{Cl}+\mathrm{H}+\mathrm{M}$ & $8.36 \mathrm{e}+13$ & 0 & 82417 \\
\hline 24 & $\mathrm{HCl}+\mathrm{OH} \rightleftharpoons \mathrm{Cl}+\mathrm{H}_{2} \mathrm{O}$ & $4.83 \mathrm{e}+07$ & 1.60 & -214 \\
\hline
\end{tabular}

\subsection{Genetic algorithm}

A genetic algorithm searches for the optimal solution of a problem by applying the principles of natural selection and evolution to an initialized population of potential solutions [45]. In the present work, genetic algorithm is employed to optimize the kinetic parameters of the reduced mechanism obtained via DRGEP, i.e., the pre-exponential factor $A_{j}$, the temperature exponent $\beta_{j}$, and the activation energy $E_{j}$. Here, $a_{j}=\log A_{j}$ is introduced to eliminate the effects of high values associated to $A_{j}$. A chromosome is constituted of a set of the three parameter values $\left(a_{j}, \beta_{j}, E_{j}\right)$, 
while each parameter value is a gene. A set of 48 chromosomes, i.e., the population of the genetic algorithm problem $M=48$, is applied with an allowed variation of $\pm 8 \%$ for each of the three chemical parameters. The kinetic rates of the resulting optimal reduced mechanism are given in Table 3. The corresponding relative variations of the chemical parameters of the elementary reactions are shown in \% in Fig. 1

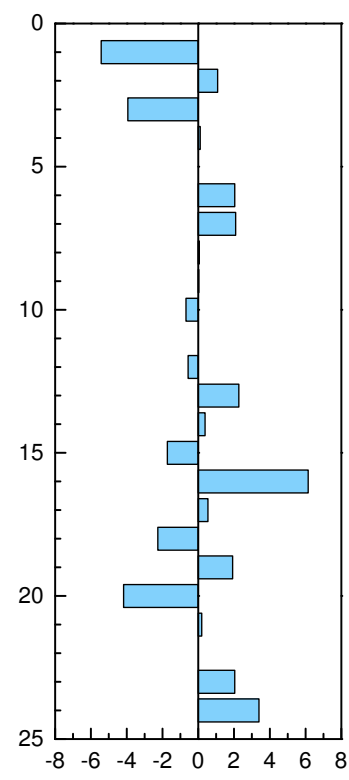

(a) $\log (A)$

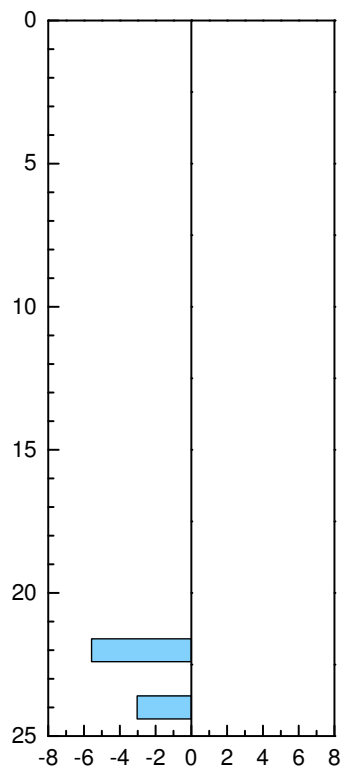

(b) $\beta$

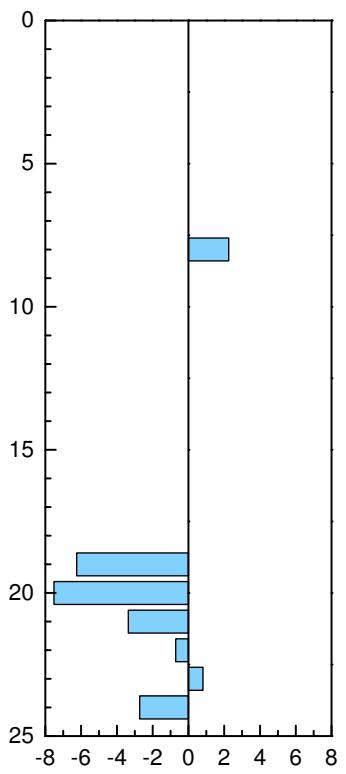

(c) $E$

Figure 1: Variation of the rate parameters of the reduced mechanism in \% measured from the detailed reference mechanism [23]. Reactions are ordered as in Table 3

Figures 2 and 3 show the evolutions of temperature and mass fractions of major species for the detailed mechanism [23], the optimized reduced mechanism of Table 3 and the preliminary reduced mechanism (DRGEP, Table 3 but with original rates parameters). The trajectories issued from fuel, oxidizer and the third coflow inlets are displayed. It can be observed that the hydrocarbon combustion is perfectly reproduced by the reduced mechanism (either with the optimized or the original rates parameters) and the ignition occurring around $0.5 \mathrm{~ms}$ is also well captured (Fig. 2). Indeed, the same DRM22 mechanism is employed to describe the hydrocarbon oxidation, combined with the detailed or the reduced mechanisms for potassium chemistry. Since the non-hydrocarbon components, i.e., $\mathrm{K} / \mathrm{Cl} / \mathrm{S}$ species, are minor in the volatile gas, the influence of 
the potassium chemistry on the hydrocarbon combustion should be marginal.

For the dynamics of potassium chemistry, all the four major potassium species reach their peak mass fractions around the ignition time, especially for the fuel trajectory (Fig. 3). This should be attributed to the production of radicals from the actively combustion process, which activates the potassium chemistry (see Table 3). Subject to random mixing, the radicals quench and the concentration of potassium species drops, to then slowly evolves towards the equilibrium. Comparing the results from the preliminary reduced mechanism based on the original rates parameters, the reduced mechanism with rates parameters optimized by the genetic algorithm shows a better agreement with the detailed reference, especially for the trajectories of $\mathrm{K}_{2} \mathrm{SO}_{4}$. As shown in Figs. 3(d) and 4, the predictions of reduced mechanism on $\mathrm{K}_{2} \mathrm{SO}_{4}$ are significantly improved when the optimized rates parameters are employed. It confirms the advantage in adding the optimization of the rate parameters by the genetic algorithm to better predict minor pollutant species, specifically considering the fact that the number of sulfur containing species has been heavily reduced by $73 \%$ from 22 to 6 by DRGEP.

Note that the presence of $\mathrm{KCl}$ in gaseous form at the beginning of fuel stream trajectory (Fig. 3(c)), is justified by the fact that once the chemical reactions are activated for the volatile fuel, $\mathrm{KCl}$ is produced at $300 \mathrm{~K}$. First, $\mathrm{K}_{2} \mathrm{O}_{2} \mathrm{H}_{2}$ is produced via $2 \mathrm{KOH} \rightleftharpoons \mathrm{K}_{2} \mathrm{O}_{2} \mathrm{H}_{2}$. Second, $\mathrm{KOH}$ reacts with $\mathrm{HCl}$ in the volatile fuel by $\mathrm{KOH}+\mathrm{HCl} \rightleftharpoons \mathrm{KCl}+\mathrm{H}_{2} \mathrm{O}$, and $\mathrm{KCl}$ subsequently forms $\mathrm{K}_{2} \mathrm{Cl}_{2}$ through $2 \mathrm{KCl} \rightleftharpoons \mathrm{K}_{2} \mathrm{Cl}_{2}$. In real biomass combustion, the potassium species should be in condensed form at low temperature and therefore the results in the unburned region of the canonical micro-mixing problem are questionable. However, this artifact hopefully disappears in the pulverized-biomass flames discussed thereafter, since the potassium is released along with volatile at a much higher temperature.

\section{Evaluation of the reduced mechanism in $2 \mathrm{D}$ pulverized-biomass flame}

\subsection{DNS flow configuration}

A two-dimensional direct numerical simulation (DNS) of a temporally evolving pulverizedbiomass jet flame with potassium emission is now performed with the reduced mechanism (Fig. 


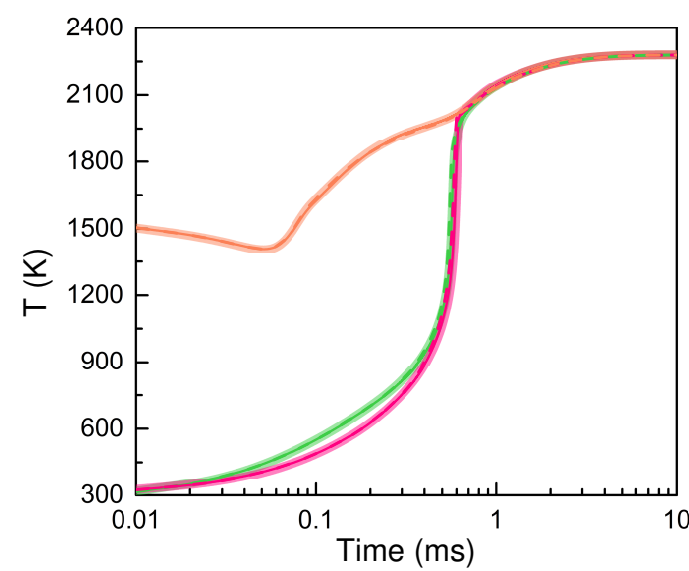

(a) Temperature

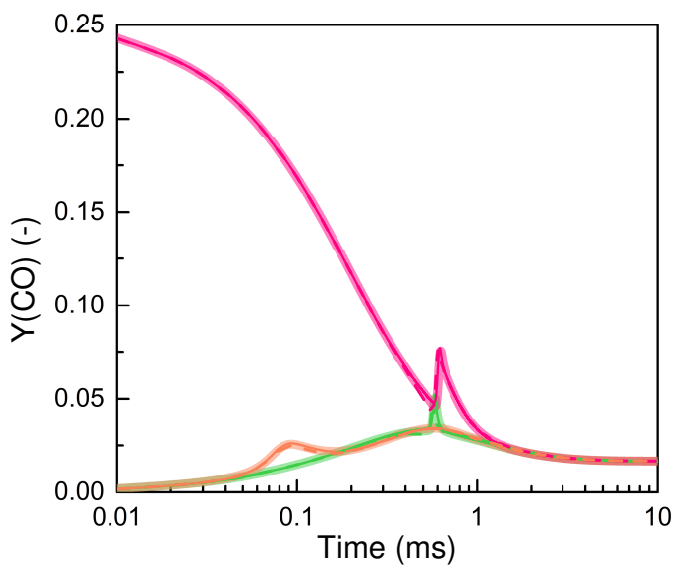

(c) $\mathrm{CO}$

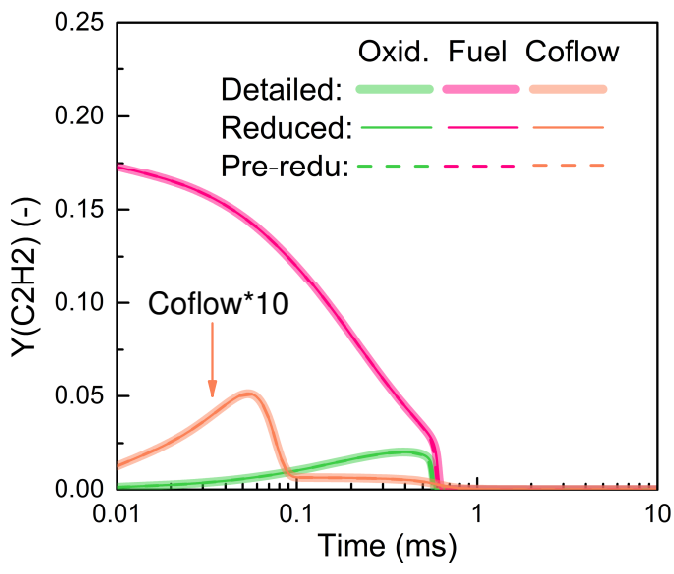

(e) $\mathrm{C}_{2} \mathrm{H}_{2}$

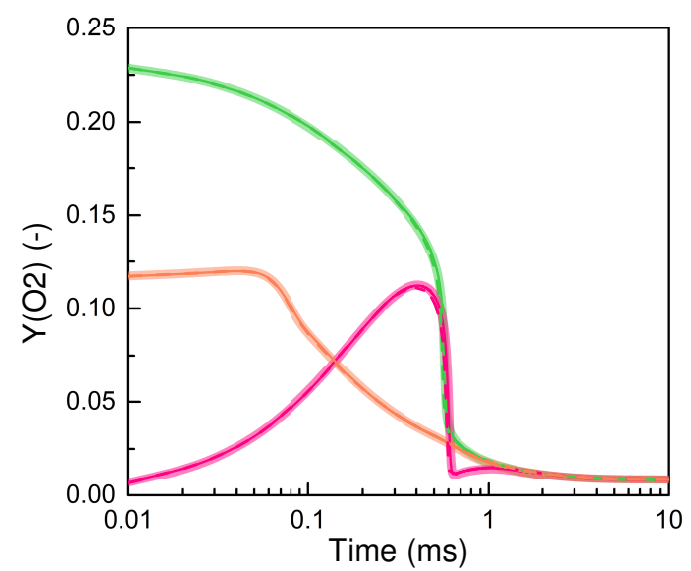

(b) $\mathrm{O}_{2}$

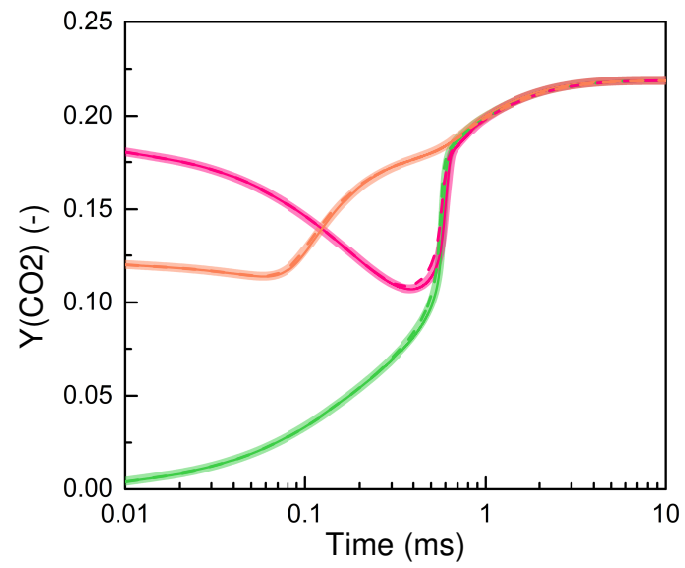

(d) $\mathrm{CO}_{2}$

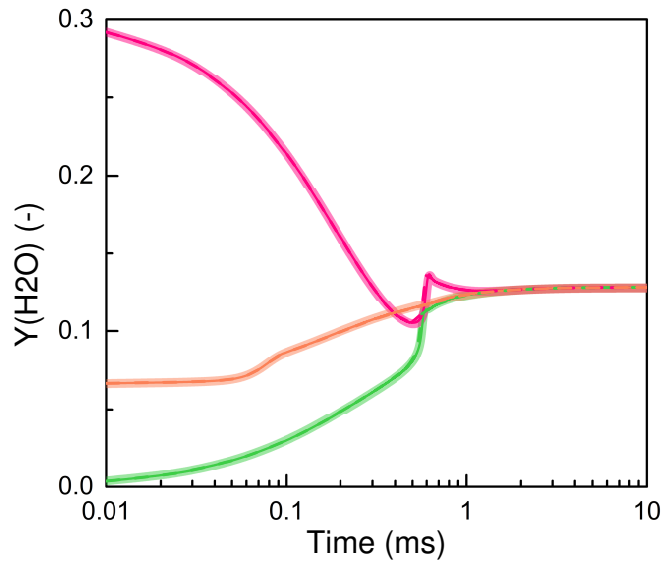

(f) $\mathrm{H}_{2} \mathrm{O}$

Figure 2: Time evolution of the deterministic mixing trajectories (Eq. 1). Temperature and species mass fractions. Green: from oxidizer stream. Pink: fuel stream. Orange: coflow stream. Thick solid lines: detailed mechanism [23]. Thin solid lines: reduced mechanism (Table 3). Dashed lines: preliminary reduced mechanism (DRGEP, Table 3 but with original rates parameters) 


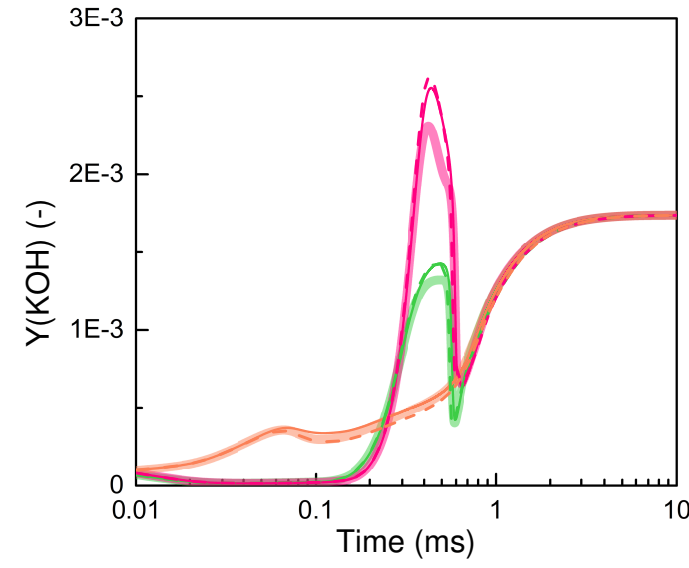

(a) $\mathrm{KOH}$

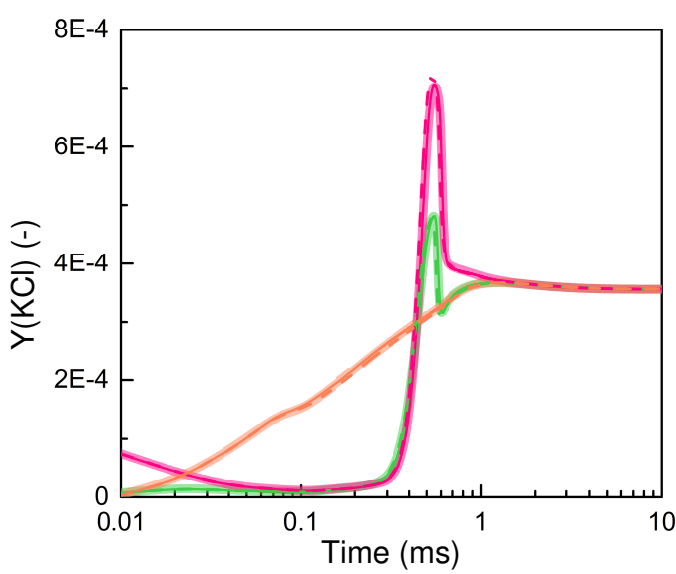

(c) $\mathrm{KCl}$

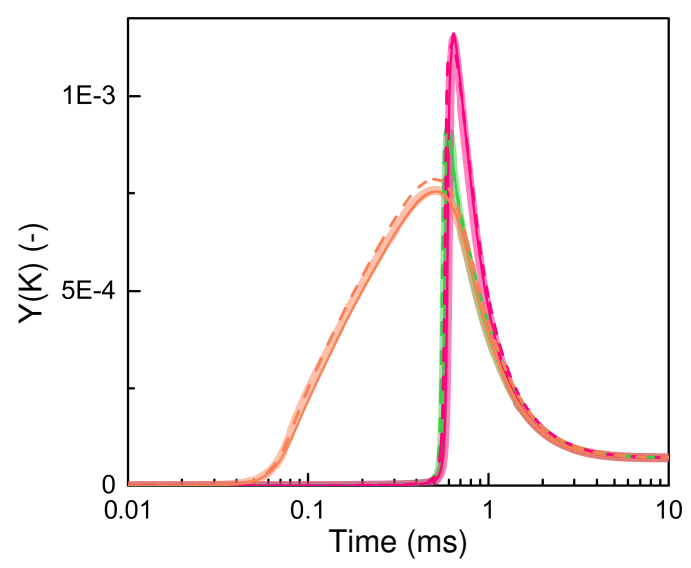

(b) $\mathrm{K}$

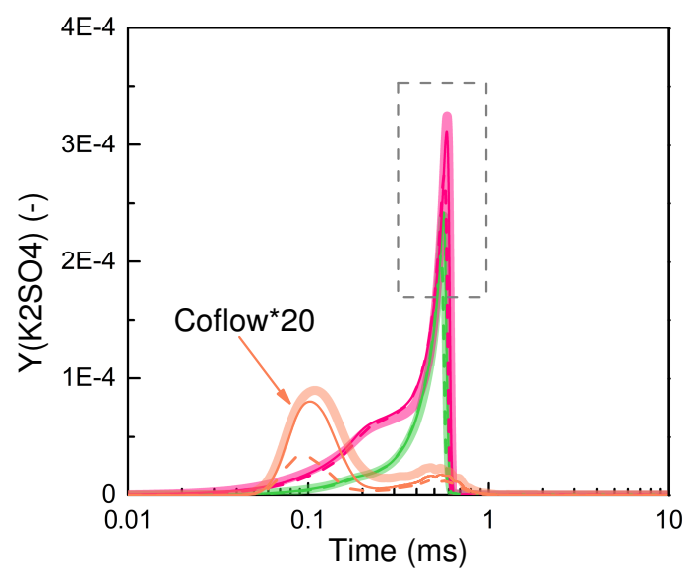

(d) $\mathrm{K}_{2} \mathrm{SO}_{4}$

Figure 3: Time evolution of the deterministic mixing trajectories (Eq. 1). Species mass fractions. Green: from oxidizer stream. Pink: fuel stream. Orange: coflow stream. Thick solid lines: detailed mechanism [23]. Thin solid lines: reduced mechanism (Table 3). Dashed lines: preliminary reduced mechanism (DRGEP, Table 3 but with original rates parameters) 


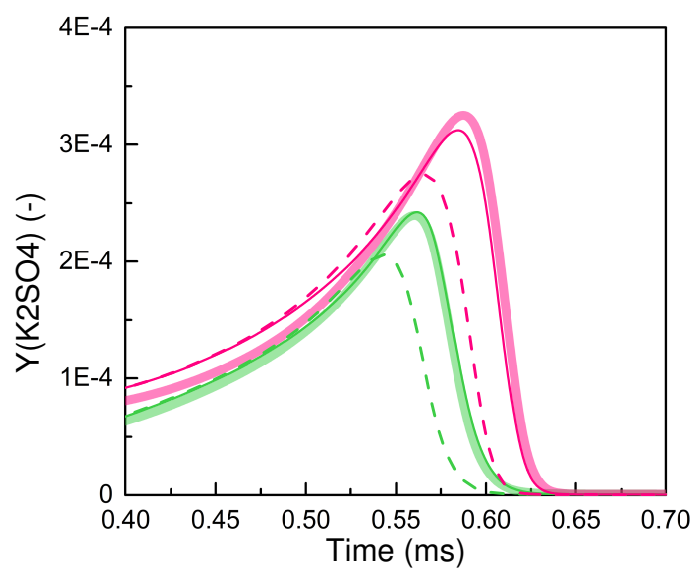

Figure 4: Time evolution of the deterministic mixing trajectories (Eq.11). $\mathrm{K}_{2} \mathrm{SO}_{4}$ mass fractions. Green: from oxidizer stream. Pink: fuel stream. Thick solid lines: detailed mechanism [23]. Thin solid lines: reduced mechanism (Table 3). Dashed lines: preliminary reduced mechanism (DRGEP, Table 3 but with original rates parameters)

5). The biomass flame operating conditions are those of [39], where the detailed configurations and numerical methods could be found. The computational domain has physical dimensions of $L_{x}=L_{y}=51.2 \mathrm{~mm}$. A uniform mesh of $\Delta=100 \mu \mathrm{m}$ is employed, which has been shown to be able to properly resolve the flame structure[46]. Primary air (bulk velocity: $10 \mathrm{~m} / \mathrm{s}, 300 \mathrm{~K}$ ) laden with 902 pulverized-biomass particles is introduced for $|y|<2.5 \mathrm{~mm}$ initially, with a hot coflow gas $(3 \mathrm{~m} / \mathrm{s}, 1519 \mathrm{~K})$ surrounded. The properties of corn straw (Table 1) is used. The coflow is the burnout gas of corn straw volatile and air at $\phi=0.45$. Biomass particles' location follows a random uniform distribution and initial particle density is $550 \mathrm{~kg} / \mathrm{m}^{3}$. The particles have a uniform diameter of $25 \mu \mathrm{m}$, to fulfill the point-particle assumption and the grid resolution required by DNS. This fine diameter could be achieved with torrefied biomass [47]. Periodic boundary conditions are introduced in all directions. Turbulent fluctuations of $0.05 \mathrm{~m} / \mathrm{s}(0.5 \%$ of the primary air velocity) are initially set within the shear layers between the primary jet and the coflow.

The simulations are performed in the Eulerian and Lagrangian frameworks with a low-Mach number in-house code specialized in turbulent solid fuel combustion [34, 39, 46, 48, 49]. The governing equations for the gas and particle phases are those of Wan et al. [39]. Biomass pyrolysis with $\mathrm{K} / \mathrm{Cl} / \mathrm{S}$ release, homogeneous volatile combustion and $\mathrm{K} / \mathrm{Cl} / \mathrm{S}$ reactions are simulated. Heterogeneous char reaction is not considered since its contribution has been shown to be minor in such a small-scale solid fuel flame [33, 49, 50]. The pyrolysis rate of a pulverized-biomass parti- 


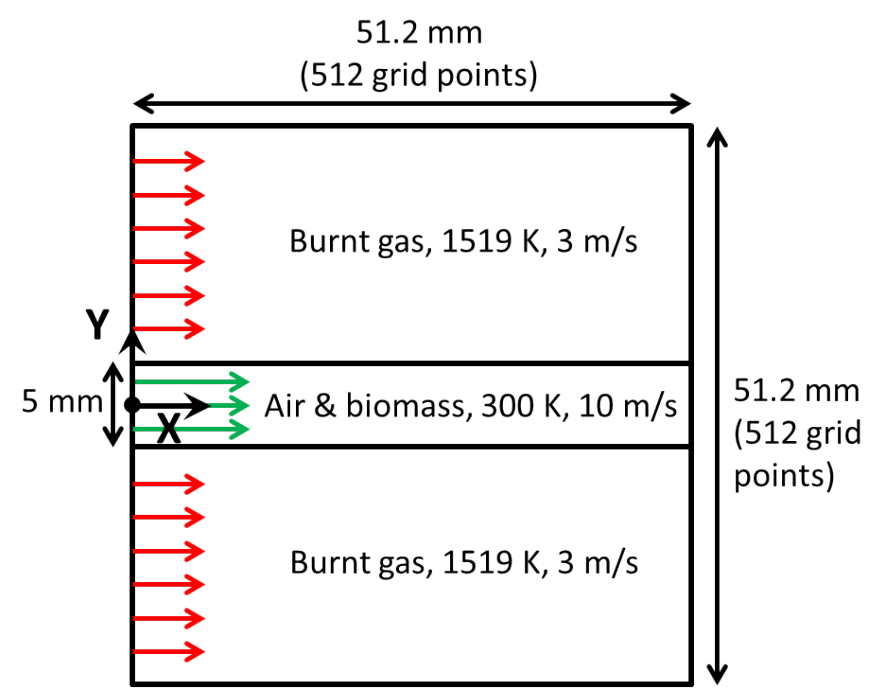

Figure 5: Schematic diagram of computational configuration of the two-dimensional DNS of pulverized-biomass flame.

cle is determined by the single first-order reaction model (SFOM) [51] with its kinetic parameters, i.e., $A_{v}\left(2.5 \times 10^{9} \mathrm{~s}^{-1}\right), E_{v}\left(11 \times 10^{4} \mathrm{~J} / \mathrm{mol}\right)$ and $Q_{v}(1.1)$, calibrated by the bio-CPD model[30], as in [34].

The hydrocarbon volatile combustion is described by the DRM22 skeleton mechanism [29], while the $\mathrm{K} / \mathrm{Cl} / \mathrm{S}$ reactions are simulated with both the detailed [23] and reduced (Table 3 ) mechanisms. As in previous works[39, 46, 49], the potassium release rate of a biomass particle is set to be proportional to its volatile release rate, because the potassium vapor generated inside the porous structure of a biomass particle will be transported outward by the volatile yielded and the experiments have shown that the alkali release is proportional to the burnout of solid fuel particles during the early combustion stage [20]. Similarly, the release rates of sulfur and chlorine are also set to be proportional to that of the volatile. The detailed composition of the volatile gas is summarized in Table 2,

\subsection{Global flame characteristics}

The performance of the reduced mechanism in the 2D pulverized-biomass flame is now examined. Figures 6 and 7 show the instantaneous distribution of the gas temperature and particle burnout, and $\mathrm{K}_{2} \mathrm{SO}_{4}$ mass fraction at five subsequent times. At the early stage of $t=10-15 \mathrm{~ms}$, 

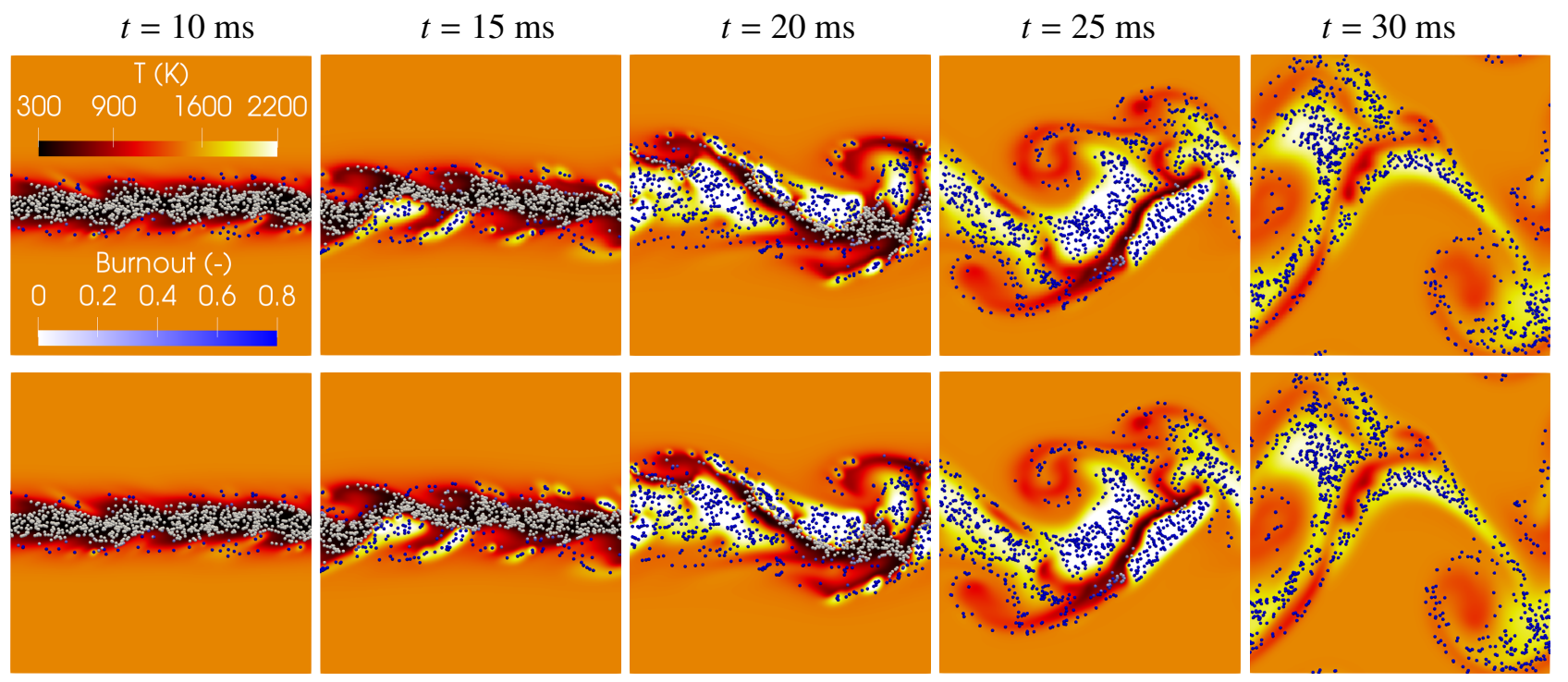

Figure 6: Instantaneous distribution of the gas temperature and particle burnout at subsequent times. Upper: detailed potassium mechanism [23]. Lower: reduced potassium mechanism (Table 3].

biomass particles in the shear layers are firstly heated up by the coflow and then yield volatiles including $\mathrm{K} / \mathrm{Cl} / \mathrm{S}$ species during the pyrolysis process. At $t=20 \mathrm{~ms}$, the heat release from the volatile oxidation is strong enough to ignite adjacent biomass particles, resulting in a rapid spreading flame. The flame in turn heats up surrounding particles and promotes the release of volatile and potassium species $\mathrm{KOH}$, which through potassium reactions forms the zones with a high concentration of $\mathrm{K}_{2} \mathrm{SO}_{4}$ in Fig. 7. Finally, at $t=30 \mathrm{~ms}$, the flame tends to be weak since most of the biomass particles burn out, while the flame region becomes wider because the turbulent mixing continues. A wide region of high concentration $\mathrm{K}_{2} \mathrm{SO}_{4}$ can be observed, which means the production of $\mathrm{K}_{2} \mathrm{SO}_{4}$ is significant. The predictions of the detailed and reduced potassium mechanisms are quite close to each other. Please note although the same DRM22 mechanism is employed for hydrocarbon combustion in both cases, the $\mathrm{K} / \mathrm{Cl} / \mathrm{S}$ reactions interact with the combustion via major species, e.g. $\mathrm{O}_{2}$, and radicals, e.g., $\mathrm{OH}$.

Figure 8 shows the comparisons between the DNS predictions using the detailed and reduced potassium mechanisms for $\mathrm{OH}, \mathrm{C}_{2} \mathrm{H}_{2}$ and $\mathrm{CO}_{2}$, and the three major potassium species, $\mathrm{KOH}, \mathrm{K}$ and $\mathrm{KCl}$ at $t=20 \mathrm{~ms}$. The prediction of the reduced potassium mechanism agrees well with that of the detailed mechanism. The good agreement on $\mathrm{OH}, \mathrm{C}_{2} \mathrm{H}_{2}$ and $\mathrm{CO}_{2}$ between the two cases 

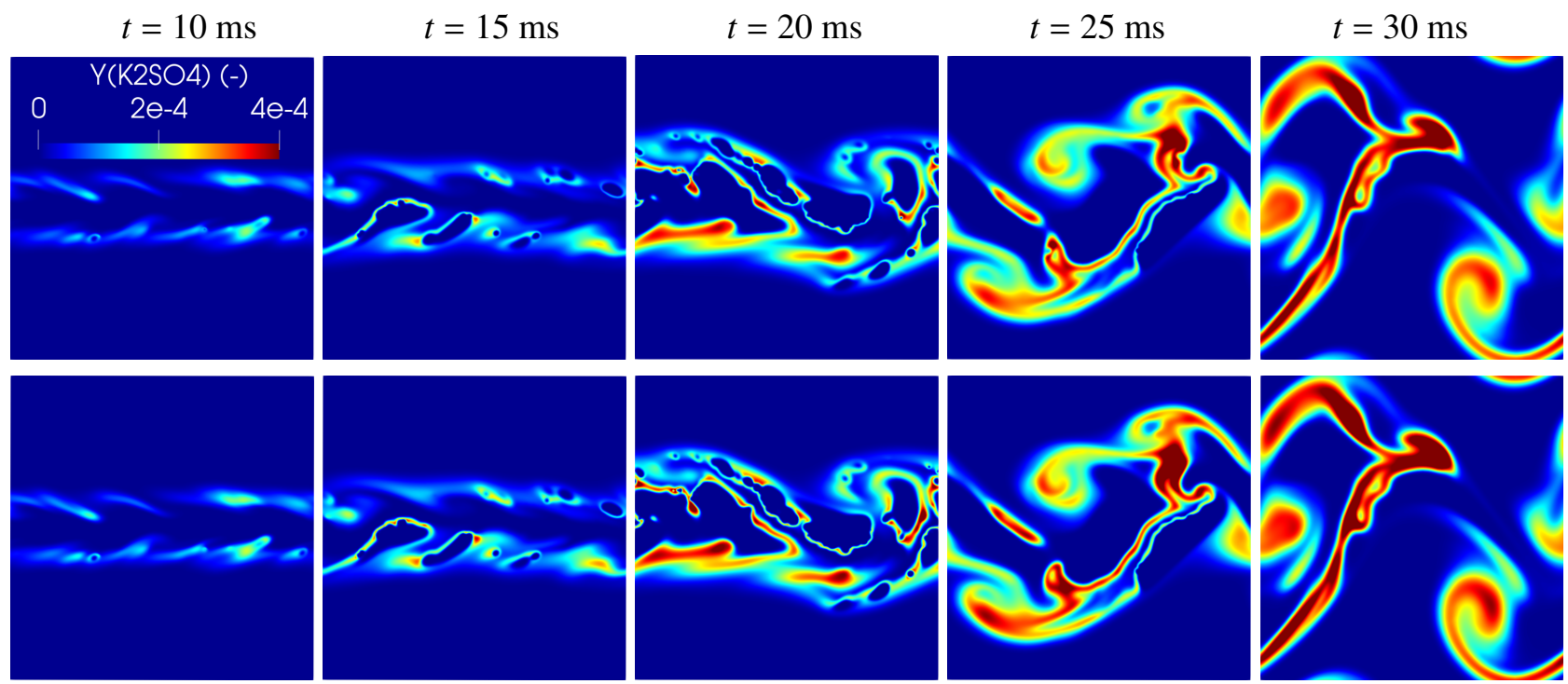

Figure 7: Instantaneous distribution of $\mathrm{Na}_{2} \mathrm{SO}_{4}$ at subsequent times. Upper: detailed potassium mechanism [23]. Lower: reduced potassium mechanism (Table 3 .

indicates the reduction of potassium chemistry does not jeopardize the accuracy of combustion prediction. For the potassium species, it can be observed that the distribution of atomic K closely follows the $\mathrm{OH}$ radical distribution, which means the production of atomic $\mathrm{K}$ is favored in the regime with strong heat release. High concentration of $\mathrm{KOH}$ appears in the region where $\mathrm{C}_{2} \mathrm{H}_{2}$ accumulates, since both of them are released together during the pyrolysis of biomass particles. $\mathrm{KCl}$ also features a high concentration in this region, which can be explained by the reaction between $\mathrm{KOH}$ and $\mathrm{HCl}$ producing $\mathrm{KCl}$ (Reaction $\mathrm{R} 9$ in Table 3 ).

\subsection{Quantitative analysis}

Figure 9 shows the scatter plots of instantaneous mass fractions of the four major potassium species against the mixture fraction $Z$ predicted by both the detailed and reduced potassium mechanisms at $t=20 \mathrm{~ms}$. The data is obtained from every grid point of the entire domain. See also Fig. 10 with $\left(\overline{Y_{i} \mid Z^{*}}\right)$ showing the conditional mixture fraction average and conditional root-meansquare (RMS), $\overline{\left[\left(\overline{Y_{i} \mid Z^{*}}\right)-Y_{i} \mid Z^{*}\right]^{2}}$, of species mass fractions. It can be observed the four major potassium species show different distribution characteristics. $Y_{\mathrm{KOH}}$ and $Y_{\mathrm{KCl}}$ are increase almost linearly with $Z$. The distribution of $Y_{\mathrm{K}}$ is more subtle. $Y_{\mathrm{K}}$ stays close to zero for the range of $Z<0.1$, to then increase rapidly until $Z=0.22$, and then keeps an overall increase trend with 


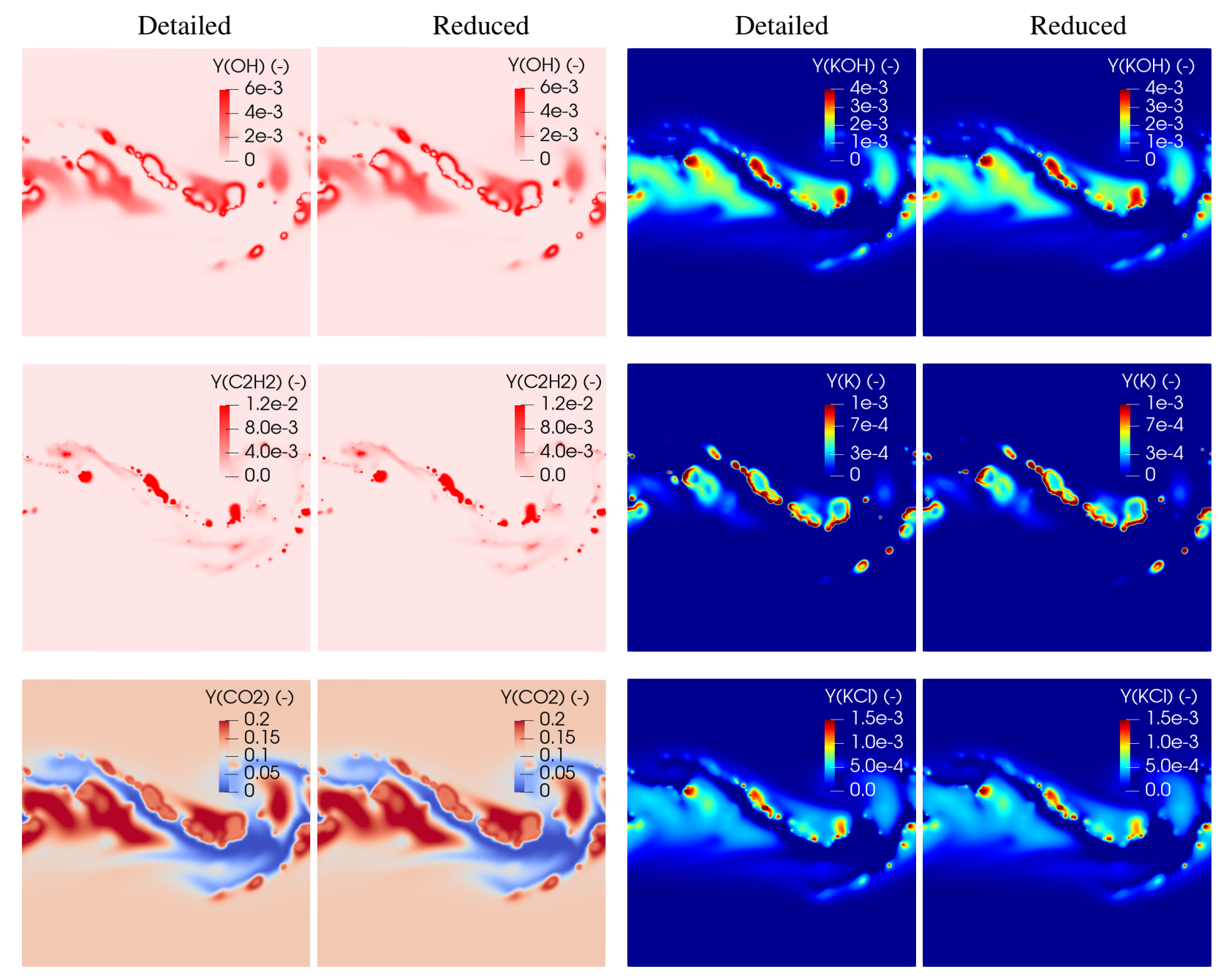

Figure 8: Mass fractions of $\mathrm{OH}, \mathrm{KOH}, \mathrm{C}_{2} \mathrm{H}_{2}, \mathrm{~K}, \mathrm{CO}_{2}$ and $\mathrm{KCl}$ at $t=20 \mathrm{~ms}$. Left columns: detailed potassium mechanism [23]. Right columns: reduced potassium mechanism (Table 3] 

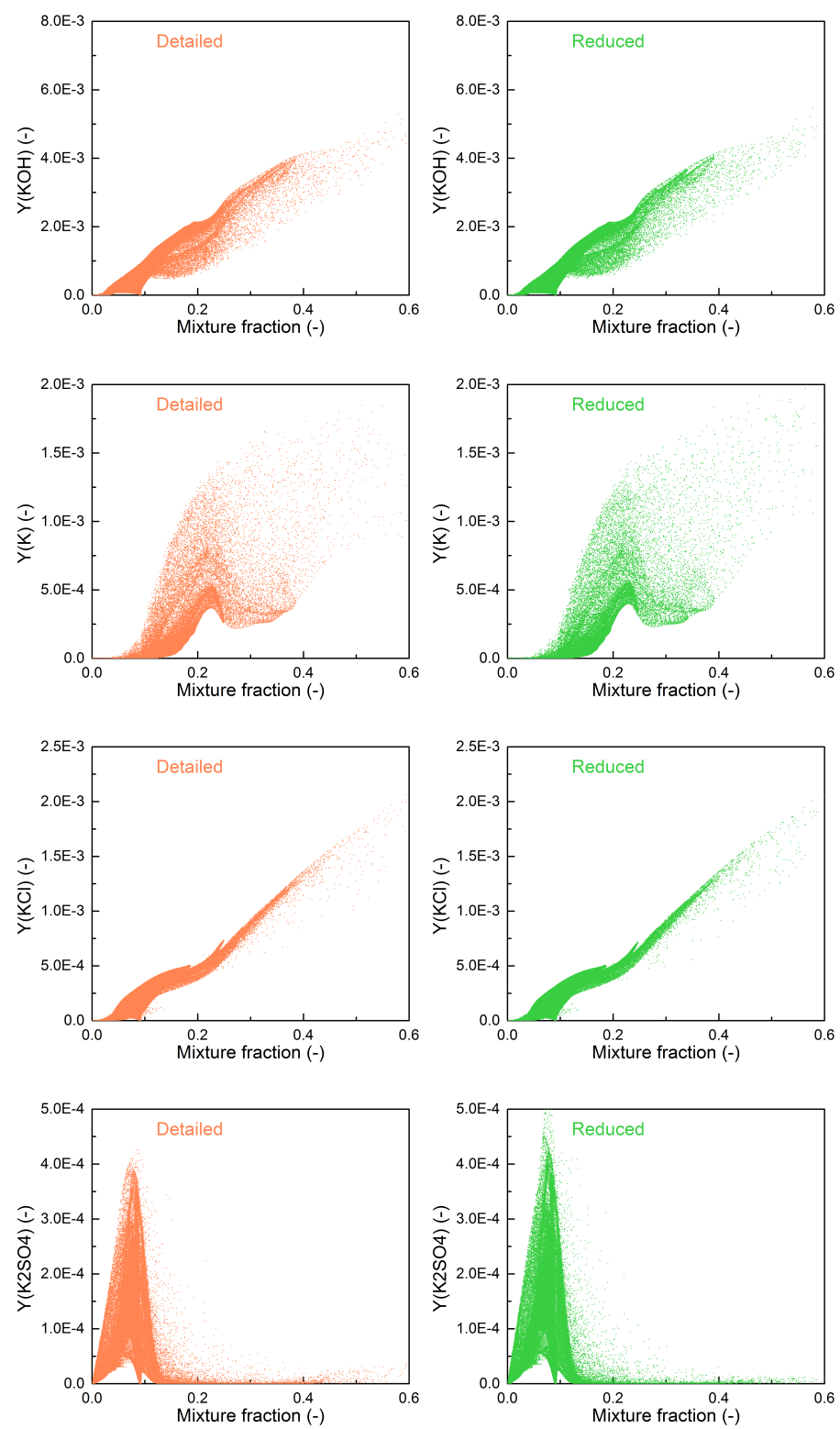

Figure 9: Scatter plots of mass fractions of $\mathrm{KOH}, \mathrm{K}, \mathrm{KCl}, \mathrm{K}_{2} \mathrm{SO}_{4}$ against mixture fractions at $t=20 \mathrm{~ms}$. Left: detailed potassium mechanism [23]. Right: reduced potassium mechanism (Table 3). 

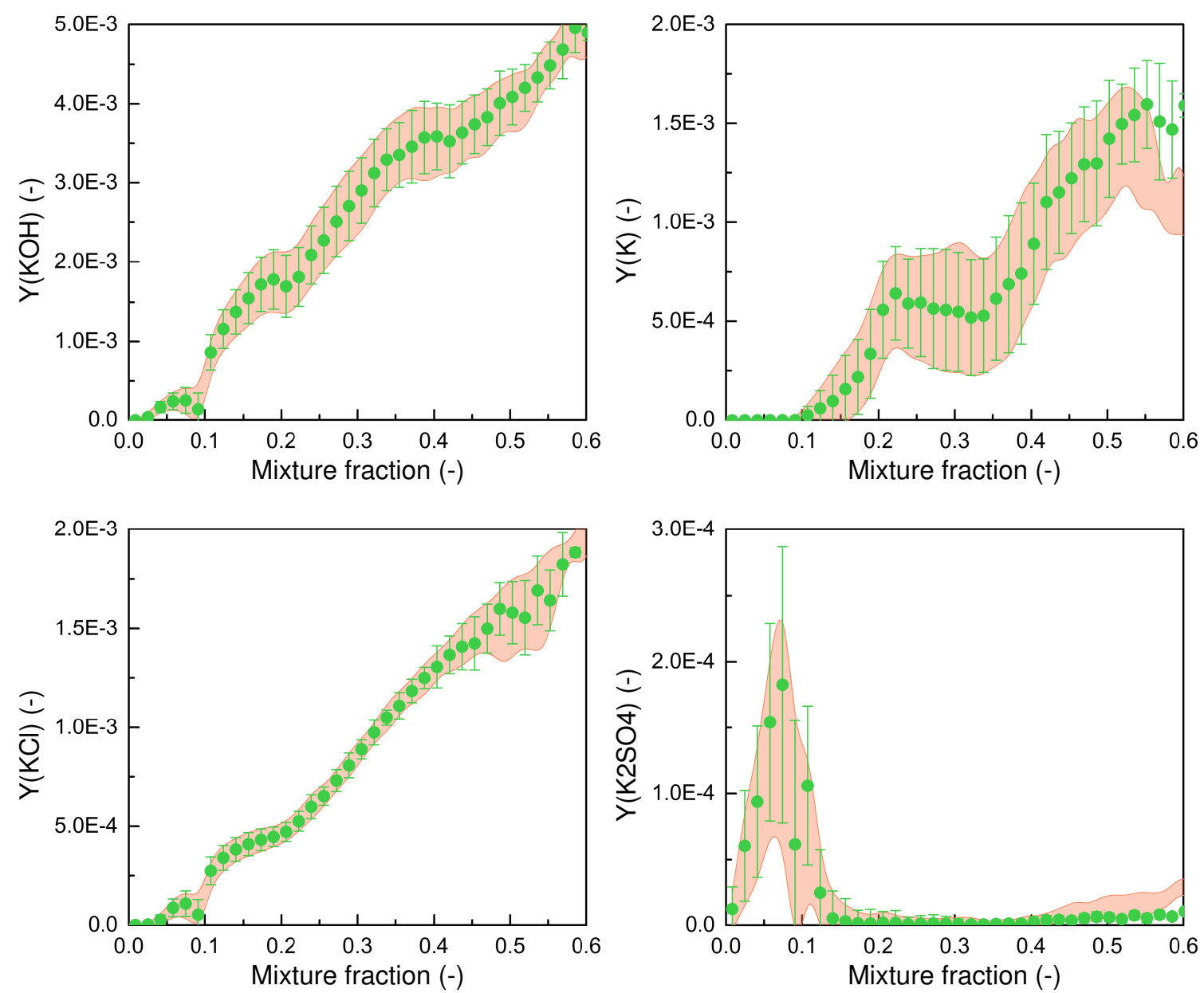

Figure 10: Conditional mixture fraction averages of mass fractions of $\mathrm{KOH}, \mathrm{K}, \mathrm{KCl}, \mathrm{K}_{2} \mathrm{SO}_{4}$ at $t=20 \mathrm{~ms}$. Range of conditional average \pm fluctuation. Orange bands: detailed potassium mechanism [23]. Symbols: reduced potassium mechanism (Table 3). 
wide fluctuations in the mixture fraction space. The sulfurous potassium product $\mathrm{K}_{2} \mathrm{SO}_{4}$ features a single-peak distribution in the fuel-lean regime of $Z<Z_{\mathrm{st}}=0.189$. Due to the influence of the coflow stream (equivalence ratio of 0.45 and $Z=0.093$ ) which does not carry potassium species, mass fractions of the four potassium species could reach zero at $Z=0.093$. The comparison on conditional average and RMS of the potassium species mass fractions (Fig. 10) confirms the accuracy of the reduced potassium mechanism.

Figure 11 shows the time evolutions of the mass fractions of $\mathrm{OH}, \mathrm{HCl}, \mathrm{SO}_{2}, Z_{\mathrm{vol}}$, of the four major potassium species and of gas temperature, all of which are averaged over the entire computational domain. $Z_{\mathrm{vol}}$ is the volatile mixture fraction, which is a transported scalar with a source term representing the volatile mass released from biomass particles. It can be observed that both the gas temperature and $Z_{\mathrm{vol}}$ start to increase around $t=5 \mathrm{~ms}$, indicating the first ignition of the biomass jet. During $t \in[15,20] \mathrm{ms}$, the mass fractions of all the species as well as the gas temperature increase rapidly, which should be attributed to the actively burning of the biomass flame. Both the averaged gas temperature and $Z_{\mathrm{vol}}$ become constant after $t=30 \mathrm{~ms}$, which means the combustion is completed. Nevertheless, the variance of gas temperature is further decreasing because of the turbulent mixing between the burnout gases and the surroundings, which therefore explains the decreasing of $Y_{\mathrm{OH}}$ and $Y_{\mathrm{HCl}}$ after $t=30 \mathrm{~ms}$. Toward the end of the simulation at $t=50 \mathrm{~ms}$, the mass fraction of $\mathrm{KCl}$ is higher than that of $\mathrm{K}_{2} \mathrm{SO}_{4}$. However, the concentration of $\mathrm{HCl}$ is an order of magnitude lower than that of $\mathrm{SO}_{2}$, which indicates that $\mathrm{HCl}$ has a much stronger ability to react with potassium species than $\mathrm{SO}_{2}$. A close agreement between the detailed and reduced potassium mechanisms is reached.

\section{Evaluation of the reduced mechanism under different $\mathrm{K} / \mathrm{Cl} / \mathrm{S}$ concentrations}

To illustrate the adaptability of of the reduced mechanism to various molar ratio of $\mathrm{K} / \mathrm{Cl} / \mathrm{S}$ in the volatile compositions, a parametric study is performed with different $\mathrm{K} / \mathrm{Cl} / \mathrm{S}$ concentration. As summarized in Table 4, Case A is the original condition employed in the previous Section 3, which is used as the baseline. Cases $\mathrm{B}, \mathrm{C}$ and $\mathrm{D}$ remove the $\mathrm{HCl}$ or $\mathrm{SO}_{2}$, or both of them, from the volatile to explore the performance of the reduced mechanism in the absence of $\mathrm{Cl}$ and/or $\mathrm{S}$. Since the content of $\mathrm{K}$ in the basline Case $\mathrm{A}$ is high for securing the combination with $\mathrm{Cl}$ and $\mathrm{S}$ to 


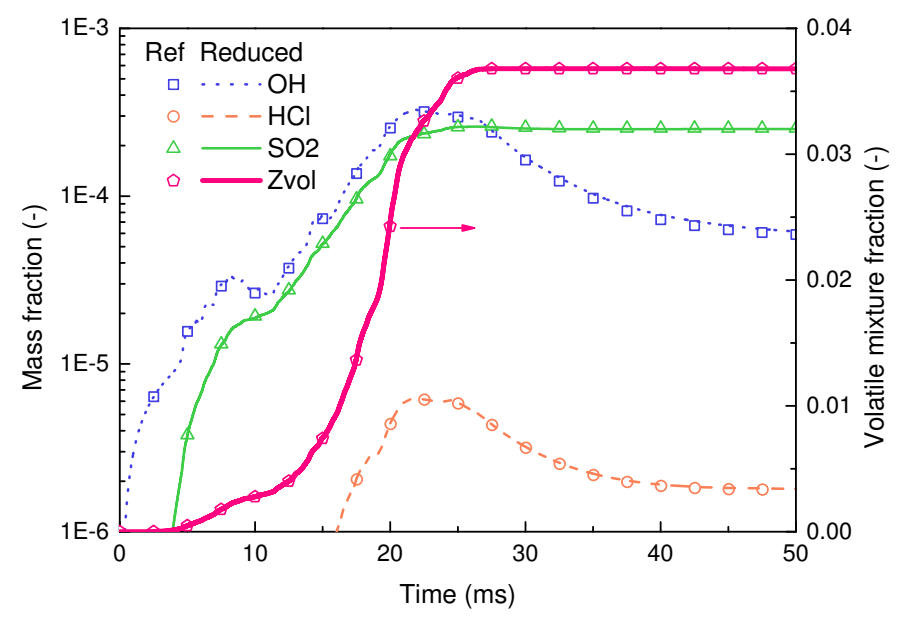

(a) mass fractions of $\mathrm{OH}, \mathrm{HCl}, \mathrm{SO}_{2}$ and $Z_{\mathrm{vol}}$

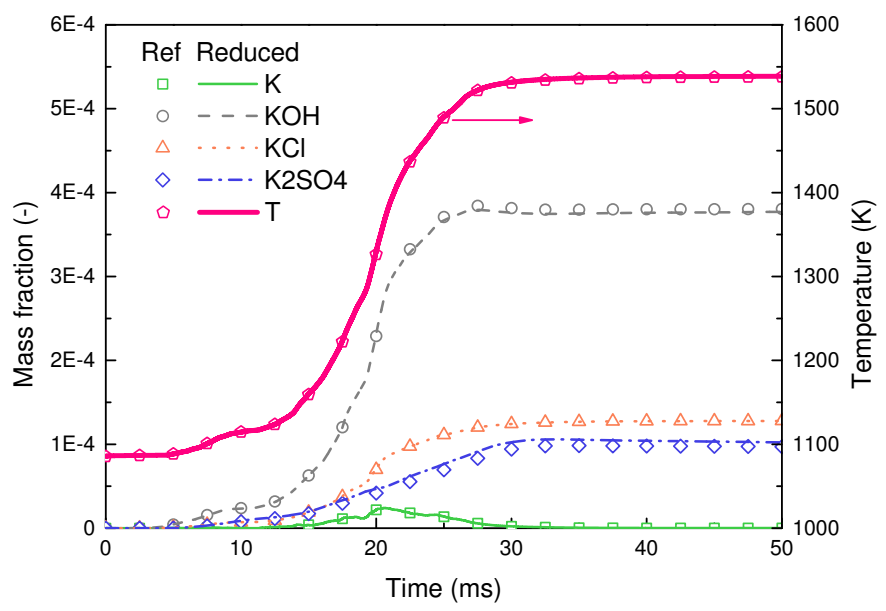

(b) mass fractions of major sodium species and gas temperature

Figure 11: Time evolutions of the mass fraction of species and volatiles $\left(Z_{\mathrm{vol}}\right)$ and gas temperature averaged over the computational domain. Symbols: detailed potassium mechanism [23]. Lines: reduced potassium mechanism (Table 3). 
Table 4: Simulation cases with different mass fractions of $\mathrm{HCl}$ and $\mathrm{SO}_{2}$ in the volatile compositions. The corresponding molar ratio of $\mathrm{K} / \mathrm{Cl} / \mathrm{S}$ of each case is also illustrated. The reduced part of $\mathrm{KOH} / \mathrm{HCl} / \mathrm{SO}_{2}$ is balanced by $\mathrm{N}_{2}$.

\begin{tabular}{lllll}
\hline Case & $\mathrm{KOH}$ & $\mathrm{HCl}$ & $\mathrm{SO}_{2}$ & $\mathrm{~K} / \mathrm{Cl} / \mathrm{S}$ molar ratio \\
\hline $\mathrm{A}$ (baseline) & $14.7 \mathrm{E}-3$ & $1.8 \mathrm{E}-3$ & $8.0 \mathrm{E}-3$ & $1 / 0.19 / 0.48$ \\
$\mathrm{~B}$ & $14.7 \mathrm{E}-3$ & 0 & $8.0 \mathrm{E}-3$ & $1 / 0 / 0.48$ \\
$\mathrm{C}$ & $14.7 \mathrm{E}-3$ & $1.8 \mathrm{E}-3$ & 0 & $1 / 0.19 / 0$ \\
$\mathrm{D}$ & $14.7 \mathrm{E}-3$ & 0 & 0 & $1 / 0 / 0$ \\
$\mathrm{E}$ & $2.76 \mathrm{E}-3$ & $1.8 \mathrm{E}-3$ & $1.58 \mathrm{E}-3$ & $1 / 1 / 0.5$ \\
$\mathrm{~F}$ & $2.76 \mathrm{E}-3$ & $0.9 \mathrm{E}-3$ & $1.58 \mathrm{E}-3$ & $1 / 0.5 / 0.5$ \\
$\mathrm{G}$ & $2.76 \mathrm{E}-3$ & $0.9 \mathrm{E}-3$ & $8.0 \mathrm{E}-3$ & $1 / 0.5 / 2.53$ \\
\hline
\end{tabular}

form $\mathrm{KCl}$ and $\mathrm{K}_{2} \mathrm{SO}_{4}$, Cases $\mathrm{E}, \mathrm{F}$ and $\mathrm{G}$ are set up to study the response of the reduced mechanism under a lower concentration of potassium.

Each case in Table 4 is simulated twice with both the detailed and reduced potassium mechanisms. Figure 12 shows the time evolutions of the averaged mass fractions of the four major potassium species among Cases A-D of Table 4. It can be observed that the profiles of $\mathrm{K}$ are similar among the four cases, which reach a peak value around $t=22 \mathrm{~ms}$ and then gradually decrease to negligible concentrations at the end of simulations. When both $\mathrm{HCl}$ and $\mathrm{SO}_{2}$ are removed from the volatile, $\mathrm{KOH}$ becomes the only major sodium product at the end of $t=50 \mathrm{~ms}$ (Case D). If $\mathrm{HCl}$ is removed but $\mathrm{SO}_{2}$ remains, $\mathrm{KOH}$ is then partly transformed to $\mathrm{K}_{2} \mathrm{SO}_{4}$, with both of them being main potassium products (Case B). Similarly, if $\mathrm{SO}_{2}$ gets removed but $\mathrm{HCl}$ remains, $\mathrm{KOH}$ is partly consumed by $\mathrm{HCl}$ to generate $\mathrm{KCl}$ as another main potassium product (Case $\mathrm{C}$ ). In all of the Cases $\mathrm{A}-\mathrm{D}, \mathrm{KOH}$ keeps to be the potassium product with highest mass fraction, which indicates the excessive part of potassium tends to form $\mathrm{KOH}$ in the post-combustion gases after reacting with $\mathrm{Cl}$ and $\mathrm{S}$.

The averaged responses of the four major potassium species in Cases E-G of Table 4 are compared in Fig. 13. The profiles of $\mathrm{K}$ are again similar among Cases $\mathrm{E}-\mathrm{G}$, which indicates the production of $\mathrm{K}$ is barely influenced by $\mathrm{Cl}$ and $\mathrm{S}$ in the volatiles. In Case $\mathrm{E}(\mathrm{K}: \mathrm{Cl}: \mathrm{S}=1: 1: 0.5)$, most of the potassium is transformed to $\mathrm{KCl}$ while the production of $\mathrm{K}_{2} \mathrm{SO}_{4}$ is negligible. When the molar ratio of $\mathrm{Cl} / \mathrm{K}$ decreases to 0.5 in Case $\mathrm{F}$, the formation of $\mathrm{KCl}$ is reduced almost by half, with a marginal amount of potassium transformed to $\mathrm{K}_{2} \mathrm{SO}_{4}$ at the $\mathrm{S} / \mathrm{K}$ ratio of 0.5 . Even though 


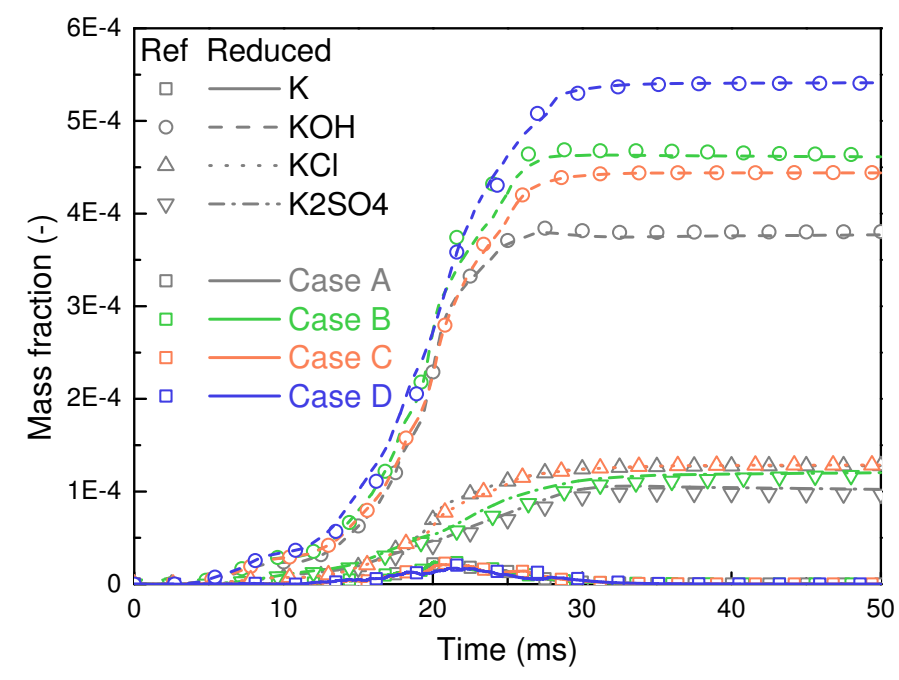

Figure 12: Time evolution of the species mass fractions averaged over the computational domain. Grey: Case A of Table 4. Green: Case B. Orange: Case C. Blue: Case D. Symbols: detailed potassium mechanism [23]. Lines: reduced potassium mechanism (Table 3).

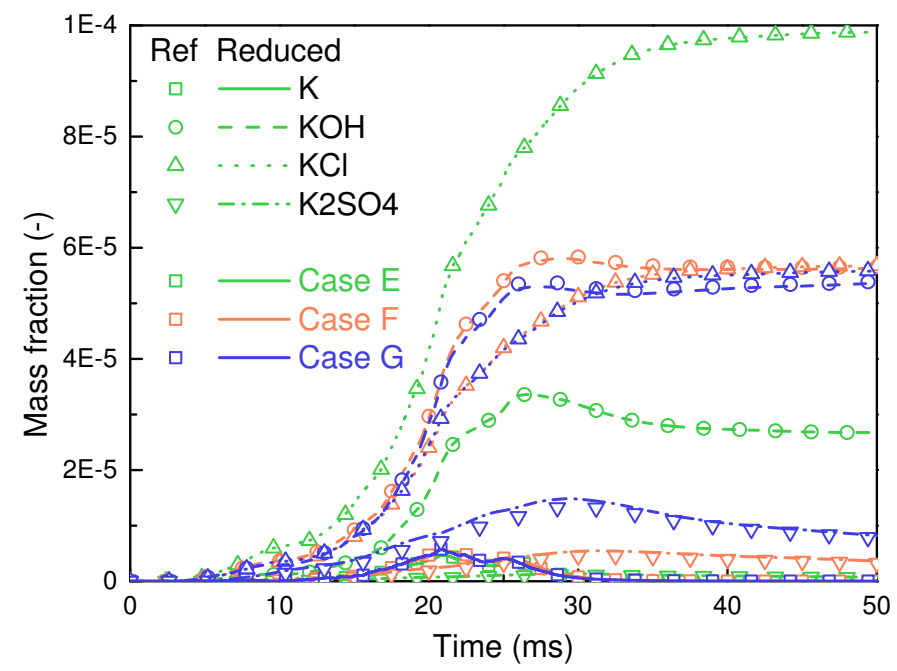

Figure 13: Time evolution of the species mass fractions averaged over the computational domain. Green: Case E of Table 4 Orange: Case F. Blue: Case G. Symbols: detailed potassium mechanism [23]. Lines: reduced potassium mechanism (Table 3 ).

the $\mathrm{S} / \mathrm{K}$ ratio is increased to 2.53 in Case $\mathrm{G}$, the formation of $\mathrm{K}_{2} \mathrm{SO}_{4}$ is still limited $\left(Y_{\mathrm{K}_{2} \mathrm{SO}_{4}}<10^{-5}\right.$ at $t=50 \mathrm{~ms}$ ). It should be partly attributed to the lower concentration of potassium in Cases $\mathrm{E}-\mathrm{G}$ than that in the baseline Case A.

The predictions of the reduced potassium mechanism agree well with that of the detailed one under all different $\mathrm{K} / \mathrm{Cl} / \mathrm{S}$ configurations (Table 4 ) in the volatile. 
These 2D DNS simulations were run over 28 Intel Boardwell cores at $2.4 \mathrm{GHz}$. The computational cost for the detailed and reduced potassium mechanisms are shown in Fig. 14. To facilitate the comparison, another 2D DNS case was performed without potassium species and reactions, which reflects the CPU cost of hydrocarbon combustion computation. After subtracting this part of CPU cost, the reduced mechanism of Table 3 saves $71.3 \%$ of the CPU cost compared to the detailed one.

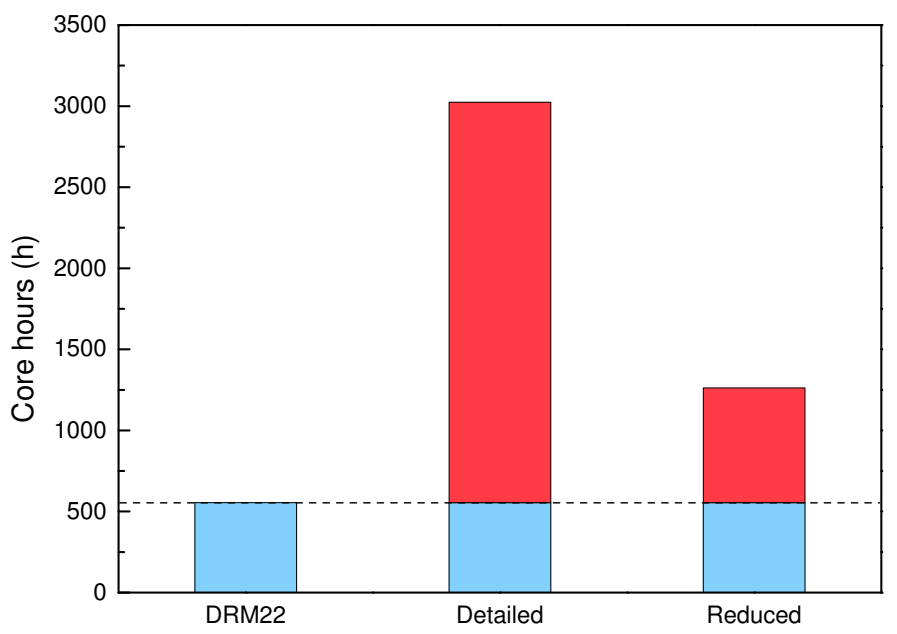

Figure 14: CPU core hours cost of running a 2D DNS case. DRM22: only hydrocarbon combustion is considered with the DRM22 mechanism [29]. Detailed: detailed potassium mechanism [23] is added to simulate potassium chemistry. Reduced: reduced potassium mechanism (Table 3) is added to simulate potassium chemistry.

\section{Conclusions}

Starting from the detailed potassium mechanism proposed by Glarborg and Marshall [23], an automated reduction and optimization strategy has been employed to develop a reduced mechanism for potassium chemistry during biomass combustion. The reduced mechanism involves $15 \mathrm{~K} / \mathrm{S} / \mathrm{Cl}$ species and 24 elementary reactions. A turbulent non-premixed micro-mixing based canonical problem has been introduced as a reference problem for the mechanism reduction and rates parameters optimization. Then, two-dimensional direct numerical simulations of turbulent pulverized-biomass flames have been performed with both the detailed and the reduced potassium mechanisms. The reduced one achieves a satisfactory prediction on potassium chemistry with a CPU cost reduction reaching up to $71.3 \%$. 
The strength of the approach discussed relies on the development of reduced mechanisms in a pre-processing manner, for given operating conditions. In the present work, the reduced potassium mechanism has been developed and validated with the detailed reference mechanism under atmospheric pressure for various $\mathrm{K} / \mathrm{Cl} / \mathrm{S}$ ratio of the volatiles in a non-premixed mixing layer featuring a piloted flame (about $1500 \mathrm{~K}$ ).

The chemistry reduction focus on the gaseous phase released from the biomass particles. The particle size is chosen according to DNS requirements and it is at the low end of a true particle-size distribution (PSD) for biomass particles. Once the reduced mechanism developed and validated, it should be applicable to a gaseous phase released from biomass particles with a real PSD.

\section{Acknowledgments}

This work was jointly supported by the National Natural Science Foundation of China (51706200), Institut Universitaire de France (IUF), the Royal Society and the Engineering and Physical Sciences Research Council (EPSRC) of the UK. Special thanks are due to Prof. Peter Glarborg of DTU, who provided us the detailed mechanism of alkali metal species. Computing resources were provided by CRIANN (http://www.criann.fr).

\section{References}

[1] H. W. Ryu, D. H. Kim, J. Jae, S. S. Lam, E. D. Park, Y.-K. Park, Recent advances in catalytic co-pyrolysis of biomass and plastic waste for the production of petroleum-like hydrocarbons, Bioresource Technology (2020) 123473.

[2] S. Singh Siwal, Q. Zhang, C. Sun, S. Thakur, V. Kumar Gupta, V. Kumar Thakur, Energy production from steam gasification processes and parameters that contemplate in biomass gasifier A review, Bioresource Technology 297 (2020) 122481.

[3] R. Sankaran, R. A. Parra Cruz, H. Pakalapati, P. L. Show, T. C. Ling, W.-H. Chen, Y. Tao, Recent advances in the pretreatment of microalgal and lignocellulosic biomass: A comprehensive review, Bioresource Technology 298 (2020) 122476.

[4] IEA, Key world energy statistics, Report (2019).

[5] Z. Xue, Z. Zhong, B. Zhang, J. Zhang, X. Xie, Potassium transfer characteristics during co-combustion of rice straw and coal, Applied Thermal Engineering 124 (2017) 1418 - 1424. 
[6] F. Li, X. Wang, C. Zhao, Y. Li, M. Guo, H. Fan, Q. Guo, Y. Fang, Influence of additives on potassium retention behaviors during straw combustion: A mechanism study, Bioresource Technology 299 (2020) 122515.

[7] H. Zhang, J. Li, X. Yang, S. Guo, H. Zhan, Y. Zhang, Y. Fang, Influence of coal ash on potassium retention and ash melting characteristics during gasification of corn stalk coke, Bioresource Technology 270 (2018) 416 -421 .

[8] S. Guo, Y. Jiang, Z. Yu, J. Zhao, Y. Fang, Correlating the sodium release with coal compositions during combustion of sodium-rich coals, Fuel 196 (2017) 252-260.

[9] Y. Niu, H. Tan, S. Hui, Ash-related issues during biomass combustion: Alkali-induced slagging, silicate meltinduced slagging (ash fusion), agglomeration, corrosion, ash utilization, and related countermeasures, Progress in Energy and Combustion Science 52 (2016) 1-61.

[10] P. J. van Eyk, P. J. Ashman, Z. T. Alwahabi, G. J. Nathan, The release of water-bound and organic sodium from Loy Yang coal during the combustion of single particles in a flat flame, Combustion and Flame 158 (6) (2011) 1181-1192.

[11] Y. Z. Liu, Z. H. Wang, K. D. Wan, Y. Lv, J. Xia, Y. He, K. F. Cen, In Situ Measurements of the Release Characteristics and Catalytic Effects of Different Chemical Forms of Sodium during Combustion of Zhundong Coal, Energy \& Fuels 32 (6) (2018) 6595-6602.

[12] P. E. Mason, J. M. Jones, L. I. Darvell, A. Williams, Gas phase potassium release from a single particle of biomass during high temperature combustion, Proceedings of the Combustion Institute 36 (2) (2017) 22072215.

[13] P. E. Mason, L. I. Darvell, J. M. Jones, A. Williams, Observations on the release of gas-phase potassium during the combustion of single particles of biomass, Fuel 182 (2016) 110-117.

[14] W. Weng, M. Costa, M. Aldén, Z. Li, Single particle ignition and combustion of pulverized pine wood, wheat straw, rice husk and grape pomace, Proceedings of the Combustion Institute 37 (3) (2019) 2663-2671.

[15] W. Weng, Q. Gao, Z. Wang, R. Whiddon, Y. He, Z. Li, M. Aldén, K. Cen, Quantitative Measurement of Atomic Potassium in Plumes over Burning Solid Fuels Using Infrared-Diode Laser Spectroscopy, Energy \& Fuels 31 (3) (2017) 2831-2837.

[16] T. Sorvajärvi, N. DeMartini, J. Rossi, J. Toivonen, In Situ Measurement Technique for Simultaneous Detection of $\mathrm{K}, \mathrm{KCl}$, and $\mathrm{KOH}$ Vapors Released during Combustion of Solid Biomass Fuel in a Single Particle Reactor, Applied Spectroscopy 68 (2) (2014) 179-184.

[17] Y. Z. Liu, Z. H. Wang, J. Xia, L. Vervisch, K. D. Wan, Y. He, R. Whiddon, H. Bahai, K. F. Cen, Measurement and kinetics of elemental and atomic potassium release from a burning biomass pellet, Proceedings of the Combustion Institute 37 (3) (2019) 2681-2688.

[18] W. Weng, S. Li, M. Costa, Z. Li, Quantitative imaging of potassium release from single burning pulverized biomass char particles, Fuel 264 (2020) 116866. 
[19] Z.-h. Zhang, Q. Song, Z. T. Alwahabi, Q. Yao, G. J. Nathan, Temporal release of potassium from pinewood particles during combustion, Combustion and Flame 162 (2) (2015) 496-505.

[20] Y. Z. Liu, Y. He, Z. H. Wang, K. D. Wan, J. Xia, J. Z. Liu, K. F. Cen, Multi-point LIBS measurement and kinetics modeling of sodium release from a burning Zhundong coal particle, Combustion and Flame 189 (2018) 77-86.

[21] S. Srinivasachar, J. J. Helble, D. O. Ham, G. Domazetis, A kinetic description of vapor phase alkali transformations in combustion systems, Progress in Energy and Combustion Science 16 (4) (1990) 303-309.

[22] M. Steinberg, K. Schofield, The chemistry of sodium with sulfur in flames, Progress in Energy and Combustion Science 16 (4) (1990) 311-317.

[23] P. Glarborg, P. Marshall, Mechanism and modeling of the formation of gaseous alkali sulfates, Combustion and Flame 141 (1-2) (2005) 22-39.

[24] K. Iisa, Y. Lu, K. Salmenoja, Sulfation of Potassium Chloride at Combustion Conditions, Energy \& Fuels 13 (6) (1999) 1184-1190.

[25] S. Akbar, U. Schnell, G. Scheffknecht, Modelling potassium release and the effect of potassium chloride on deposition mechanisms for coal and biomass-fired boilers, Combustion Theory and Modelling 14 (3) (2010) 315-329.

[26] M. U. Garba, D. B. Ingham, L. Ma, R. T. J. Porter, M. Pourkashnian, H. Z. Tan, A. Williams, Prediction of Potassium Chloride Sulfation and Its Effect on Deposition in Biomass-Fired Boilers, Energy \& Fuels 26 (11) (2012) 6501-6508.

[27] N. Jaouen, L. Vervisch, P. Domingo, G. Ribert, Automatic reduction and optimisation of chemistry for turbulent combustion modelling: Impact of the canonical problem, Combustion and Flame 175 (2017) 60-79.

[28] N. Jaouen, L. Vervisch, P. Domingo, Auto-thermal reforming (ATR) of natural gas: An automated derivation of optimised reduced chemical schemes, Proceedings of the Combustion Institute 36 (3) (2017) 3321 - 3330.

[29] A. Kazakov, M. Frenklach, Reduced reaction sets based on GRI-Mech 1.2 (1994). URL http://www.me.berkeley.edu/drm/

[30] C. D. Sheng, J. L. T. Azevedo, Modeling biomass devolatilization using the chemical percolation devolatilization model for the main components, Proceedings of the Combustion Institute 29 (2002) 407-414.

[31] K. D. Wan, Z. H. Wang, Y. He, J. Xia, Z. J. Zhou, J. H. Zhou, K. F. Cen, Experimental and modeling study of pyrolysis of coal, biomass and blended coal-biomass particles, Fuel 139 (2015) 356-364.

[32] Z. H. Wang, K. D. Wan, J. Xia, Y. He, Y. Z. Liu, J. Z. Liu, Pyrolysis Characteristics of Coal, Biomass, and CoalBiomass Blends under High Heating Rate Conditions: Effects of Particle Diameter, Fuel Type, and Mixing Conditions, Energy \& Fuels 29 (8) (2015) 5036-5046.

[33] M. Rieth, A. G. Clements, M. Rabaçal, F. Proch, O. T. Stein, A. M. Kempf, Flamelet LES modeling of coal combustion with detailed devolatilization by directly coupled CPD, Proceedings of the Combustion Institute 36 (2) (2017) 2181-2189. 
[34] K. D. Wan, J. Xia, Z. H. Wang, L. C. Wrobel, K. F. Cen, Online-CPD-coupled large-eddy simulation of pulverized-coal pyrolysis in a hot turbulent nitrogen jet, Combustion Science and Technology 189 (1) (2017) $103-131$.

[35] T. Takuwa, I. Naruse, Emission control of sodium compounds and their formation mechanisms during coal combustion, Proceedings of the Combustion Institute 31 II (2007) 2863-2870.

[36] C. Dopazo, E. E. O’Brien, Functional formulation of nonisothermal turbulent reactive flows, The Physics of Fluids 17 (11) (1974) 1968-1975.

[37] R. Borghi, Turbulent combustion modelling, Progress in Energy and Combustion Science 14 (4) (1988) 245292.

[38] R. L. Curl, Dispersed phase mixing: I. Theory and effects in simple reactors, AIChE Journal 9 (2) (1963) 175181.

[39] K. Wan, Z. Wang, J. Xia, L. Vervisch, P. Domingo, Y. Lv, Y. Liu, Y. He, K. Cen, Numerical study of HCl and SO2 impact on potassium emissions in pulverized-biomass combustion, Fuel Processing Technology 193 (2019) $19-30$.

[40] K. Bioche, G. Ribert, L. Vervisch, Simulating upstream flame propagation in a narrow channel after wall preheating: Flame analysis and chemistry reduction strategy, Combustion and Flame 200 (2019) 219 - 231.

[41] C. Locci, L. Vervisch, B. Farcy, P. Domingo, N. Perret, Selective Non-catalytic Reduction (SNCR) of Nitrogen Oxide Emissions: A Perspective from Numerical Modeling, Flow, Turbulence and Combustion 100 (2) (2018) 301-340.

[42] D. G. Goodwin, R. L. Speth, H. K. Moffat, B. W. Weber, Cantera: An Object-oriented Software Toolkit for Chemical Kinetics, Thermodynamics, and Transport Processes, https://www.cantera.org, version 2.4.0 (2018).

[43] T. Lu, C. K. Law, A directed relation graph method for mechanism reduction, Proceedings of the Combustion Institute 30 (1) (2005) 1333 - 1341.

[44] P. Pepiot-Desjardins, H. Pitsch, An efficient error-propagation-based reduction method for large chemical kinetic mechanisms, Combustion and Flame 154 (1) (2008) 67 - 81.

[45] J. H. Holland, Adaptation in Natural and Artificial Systems: An Introductory Analysis with Applications to Biology, Control and Artificial Intelligence, MIT Press, Cambridge, MA, USA, 1992.

[46] K. D. Wan, L. Vervisch, J. Xia, P. Domingo, Z. H. Wang, Y. Z. Liu, K. F. Cen, Alkali metal emissions in an early-stage pulverized-coal flame: DNS analysis of reacting layers and chemistry tabulation, Proceedings of the Combustion Institute 37 (3) (2019) 2791-2799.

[47] J. Li, E. Biagini, W. Yang, L. Tognotti, W. Blasiak, Flame characteristics of pulverized torrefied-biomass combusted with high-temperature air, Combustion and Flame 160 (11) (2013) 2585-2594.

[48] K. D. Wan, J. Xia, Z. H. Wang, M. Pourkashanian, K. F. Cen, Large-eddy Simulation of Pilot-assisted 
Pulverized-coal Combustion in a Weakly Turbulent Jet, Flow, Turbulence and Combustion 99 (2) (2017) 531550.

[49] K. D. Wan, J. Xia, L. Vervisch, Y. Z. Liu, Z. H. Wang, K. F. Cen, Modelling alkali metal emissions in large-eddy simulation of a preheated pulverised-coal turbulent jet flame using tabulated chemistry, Combustion Theory and Modelling 22 (2) (2018) 203-236.

[50] R. Knappstein, G. Kuenne, A. Ketelheun, J. Köser, L. Becker, S. Heuer, M. Schiemann, V. Scherer, A. Dreizler, A. Sadiki, J. Janicka, Devolatilization and volatiles reaction of individual coal particles in the context of FGM tabulated chemistry, Combustion and Flame 169 (2016) 72-84.

[51] S. Badzioch, P. G. W. Hawksley, Kinetics of thermal decomposition of pulverized coal particles, Industrial \& Engineering Chemistry Process Design and Development 9 (4) (1970) 521-530. 